NUREG/CR-1462

PNL-3386

\title{
Mechanistic Considerations Used in the Development of the PROFIT PCI Failure Model
}

Prepared by P. J. Pankaskie

Pacific Northwest Laboratory

Prepared for

U.S. Nuclear Regulatory

Commission 


\title{
NOTICE
}

This report was prepared as an account of work sponsored by an agency of the United States Government. Neither the United States Government nor any agency thereof, or any of their employees, makes any warranty, expressed or implied, or assumes any legal liability or responsibility for any third party's use, or the results of such use, of any information, apparatus product or process disclosed in this report, or represents that its use by such third party would not infringe privately owned rights.

\author{
Available from \\ GPO Sales Program \\ Division of Technical Information and Document Control \\ U.S. Nuclear Regulatory Conmission \\ Washington, D.C. 20555
}

and

National Technical Information Service

Springfield, Virginia 22161 


\section{Mechanistic Considerations Used in the Development of the PROFIT PCI Failure Model}

Manuscript Completed: March 1980

Date Published: May 1980

Prepared by

P. J. Pankaskie

Pacific Northwest Laboratory

P.O. Box 999

Richland, WA 99352

Prepared for

Division of Systems Integration

Office of Nuclear Reactor Regulation

U. S. Nuclear Regulatory Commission

Washington, D.C. 20555

NRC FIN No. B-2171-0 



\section{ABSTRACT}

A fuel Pellet-Zircaloy Cladding (thermo-mechanical-chemical) Interactions (PCI) failure model for estimating the probability of failure in transient increases in power (PROFIT) was developed. PROFIT is based on 1) standard statistical methods applied to available PCI fuel failure data and 2) a mechanistic analysis of the environmental and strain-rate-dependent stress versus strain characteristics of Zircaloy cladding. The statistical analysis of fuel failures attributable to PCI suggested that parameters in addition to power, transient increase in power, and burnup are needed to define PCI fuel failures in terms of probability estimates with known confidence limits. The PROFIT model, therefore, introduces an environmental and strain-rate dependent strain energy absorption to failure (SEAF) concept to account for the stress versus strain anomalies attributable to interstitial-disloction interaction effects in the Zircaloy cladding. Assuming that the power ramping rate is the operating corollary of strain-rate in the Zircaloy cladding, then the variables of first order importance in the PCI fuel failure phenomenon are postulated to be:

1. pre-transient fuel rod power, $P_{i}$,

2. transient increase in fuel rod power, $\Delta P$,

3. fuel burnup, Bu, and

4. the constitutive material property of the Zircaloy cladding, SEAF. 



\section{CONTENTS}

ABSTRACT

1.0 INTRODUCTION $\quad . \quad$. . . . . . . . . . . .

2.0 THE DATA BASE . . . . . . . . . . . . . . . . . . . . 3

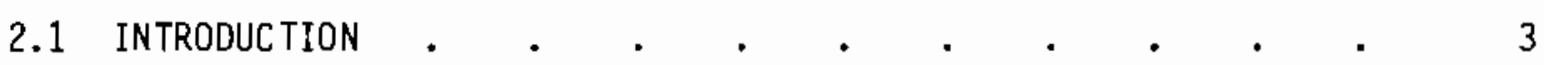

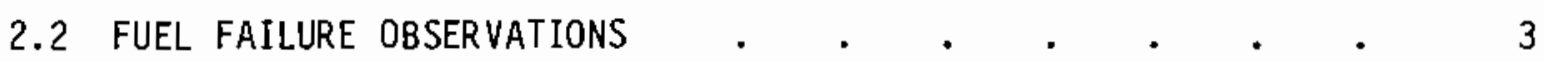

2.3 ZIRCALOY CLADOING DEFORMATION AND FAILURE CHARACTERISTICS • 11

2.3.1 Strain-Rate Oependent Plastic Deformation in Zircaloy 11

2.3.2 Strain-Rate Dependent SCC Embrittlement in Zircaloy . 23

2.3.3. Summary of Strain-Rate Effects . . . . . 29

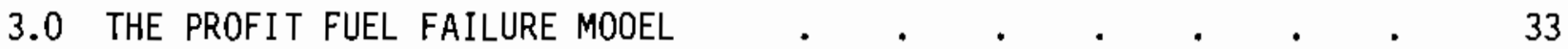

3.1 MODELING CONSIDERATIONS $\quad$ • . . . . . . . . . . 33

3.2 DEVELOPMENT OF A FAILURE FUNCTION . • • • • . . . . 37

3.3 CORROBORATION FOR THE COSH FUNCTION..$\quad$. . . . . 45

3.4 OTHER PCI FUEL FAILURE PARAMETERS . . . . . . . . . 47

3.5 FAILURE PROBABILITY . $\quad . \quad$. $\quad . \quad$. $\quad . \quad$. 53

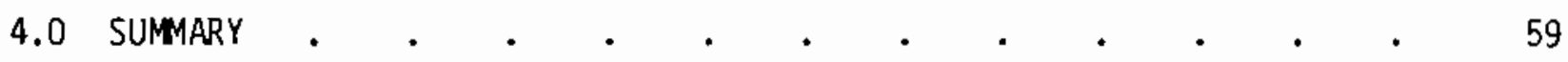

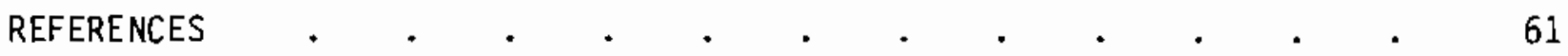




\section{FIGURES}

2.1 Data Sets 1 Through 5 Are Shown Collapsed on the $P_{j}$ versus $B u, P_{j}$ versus $\Delta P$, and $\Delta P$ versus $B u$ Planes. Non-failed and Failed Data are Identified by Number and Letter, Respectively.

2.2 Data Sets 1 Through 5 Are Shown In An Isometric View Using the Parameter $P_{j}, \Delta P$ and Bu. Non-failed and Failed Data are Identified by Number and Letter, Respectively.

2.3 Effects of Hydrogen Content, Strain Rate, and Temperature on the Tensile Ductility of a Typical $\alpha / \beta$ Titanium Alloy. From "The Hydrogen

Embrittlement of Titanium Alloys," D. N. Williams, The Journal of the Institute of Metals, Vol. 91, 1962-63 [56].

2.4 Hydrogen Embrittlement of Niobium as Shown by Curves of Reduction in Area Versus Testing Temperature. Reprinted by permission of R. E. Reed-Hill, University of Florida, Gainesville, Florida, from "Slow Strain-Rate Embrittlement in Metals," J. R. Donoso, A.T. Santhanam and Prof. R. E. Reed-Hill, Second International Conference on Mechanical Behavior of Materials, 1976 [41].

2.5 The Strain-Rate Dependence of the Reduction-in-Area Versus Testing Temperature Curves of a Commercial Purity Titanium Containing $0.4 \mathrm{a} / \mathrm{o}$ oxygen. Reprinted by permission of R. E. Reed-Hill, University of Florida, Gainesville, Florida, from "Slow Strain-Rate Embrittlement in Metals," J. R. Donoso, A.T. Santhanam and Prof. R. E. Reed-Hill, Second International Conference on Mechanical Behavior of Materials, 1976 [41].

2.6 When a More Extensive Set of Data is Used, a Log Yield Stress-Temperature Plot Shows Regions in Which the Curves Deviate from Linearity. In These Regions, Strain Aging Phenomena are Observed. Curves Corresponding to Zirconium Specimen's Deformed at Two Strain Rates are Shown. Reprinted by permission of R. E. Reed-Hill, University of Florida, Gainesville, Florida, and the Metallurgical Society of AIME, 420 Commonwealth Drive, Warrenda le, Pennsylvania, 15086. Copyright ASM and The Metallurgical Society of the AIME. From Metallurgical Transactions, VI, $1970[44]$.

2.7 Postulated Tensile Stress-Stra in Behavior for Irradiated Zircaloy as Influenced by Strain Rate and the Localized Yielding Anomaiy.

2.8 The Effect of Strain Rate on the Relative Strain Energy Absorption to Failure as Determined for Available Uniaxial Tensile Data.

2.9 Effects of Various Strain Rates on the Cracking Response of a Mg-A7 Alloy in a $\mathrm{CrO}_{4}-\mathrm{Cl}$ Solution at Various Applied Current Densities. Reprinted, with permission, from the American Society for Testing and Materials, 1916 Race Street, Philadelphia, PA, 19103. Copyright ASTM STP 665, 1979 [59]. 
2.10 Dependence of the Relative Uniform Elongation on Deformation Rate and I-Concentration. Reprinted, with permission, from the American Society for Testing and Materials, 1916 Race Street, Philadelphia, PA 19103. Copyright ASTM STP 681, 1979 [64].

2.11 Stress-Time Curves in Constant Extension Rate Tests for Stress-Relieved Material (upper) and for Recrystallized Material (lower). Reprinted by permission of the American Nuclear Society, Inc., La Grange Park, IL, Copyright ANS, 1979, From Proceedings of ANS Topical Meeting on Light Water Reactor Fuel Performance, Portland, OR, April 29-May 3, 1979 [69].

2.12 The Postulated Effect of Environment and Strain Rate on the Strain Energy Absorption to Failure (SEAF).

3.1 Shown are all Failed (F) and Did Not Fail (DNF) Fuel Data for This Burnup Interval. Also Shown is a Least Squares, Nonlinear Regression Fit to the Failed Fuel Data, and Three GAPCON-THERMAL-3 Transient Simulations.

3.2 Shown are all Failed (F) and Did Not Fail (DNF) Fuel Data for This Burnup Interval. Also Shown is the Least Squares, Nonlinear Regression Fit to the Failed Fuel Data and Six Transient Simulations.

3.3 Shown are all Failed (F) and Did Not Fail (DNF) Fuel Data for This Burnup Interval. Also Shown is the Least Squares, Nonlinear Regression Fit to the Failed Fuel Data.

3.4 A Computer-Generated Plot of the Observed and the Calculated Statistical Mean Delta Power versus Burnup for a 11 PCI Data.

3.5 A Computer-Generated Plot of the Difference Between the Observed and the Calculated Statistical Mean Delta Power for all PCI Failure Data.

3.6 The Juxtaposition of Figures 2.8 and 3.5 to Suggest a Correspondence Between the Severity of the Transients in which PCI Failures Were Observed and the Strain Rate Versus Strain Energy Absorption to Failure.

3.7 Postulated Failure Distribution About The Statistical Mean Assuming No Power Ramping Rate or Strain-Rate Effects on the Strain Energy Absorption to Failure Characteristics of the Zircaloy Cladding.

3.B Postulated Failure Distribution About Each of a Family of Statistical Means, Each of Which Correspond to a Specific Power Ramping Rate.

3.9 Shown Are All Failed (F) and Did Not Fail (DNF) Fuel Data for This Burnup Interval. Also shown are the $10 \%$ and $50 \%$ Probability of Failure (POF) Curves and Three Transient Simulations.

3.10 Shown Are All Failed (F) and Did Not Fail (DNF) Fuel Data for This Burnup Interval. Alsc Shown are the $10 \%$ and $50 \%$ Probability of Failure (POF) Curves and Six Simulated Transients. 



\title{
MECHANISTIC CONSIDERATIONS USED IN THE DEVELOPMENT
}

OF THE PROFIT PCI FAILURE MODEL

\author{
by \\ P. J. Pankaskie \\ March 1980

\subsection{INTRODUCTION}

Fuel rod failures, although fractionally small under current core/plant operating restrictions [1-6], continue to be one of the principal economic restrictions on normal plant operations. The primary source of these fuel failures is generally attributed to pellet-cladding interactions (PCI) of thermo-mechanical and thermo-chemical origins [7-18]. Current operating restrictions are an acknowledgment that fuel power increases and/or abnormal operating transients pose a potential for a significant incidence of fue 1 failures by PCI.

Considerable efforts have been applied over the past few years to investigate the origins and mechanisms of the PCI fuel failure phenomenon. From these efforts, operating recommendations and several empirical fuel failure models $[12,19,20]$ have been developed. These PCI fuel failure models a11 are based on a combination of pre- $\left(P_{i}\right)$ and/or peak post-transient $\left(P_{f}\right)$ power, the transient increase in power $(\Delta P)$, burnup $(B u)$, and a time parameter usually defined as the time to fail (TTF) or the "dwe 11 time" at $P_{f}$. It is, however, doubtful whether these models are universally applicable to the PCI fuel failure phenomenon in light water reactor (LWR) fuels.

A statistical examination [21] of all available PCI fuel failure data from heavy water reactor (HWR) and LWR operating experience and much of the 
one-of-a-kind irradiation experiments data suggests that the operating parameters $P$ (either $P_{i}$ or $\left.P_{f}\right), \Delta P, B u$ and some time parameter (e.g., TTF) are inadequate for the development of a true statistical PCI fuel failure model. An examination of the experimental data derived from stress corrosion cracking (SCC) and other deformation studies suggests the probable importance of strain (E) and/or strain-rate $(\dot{\varepsilon})$ effects on the Zircaloy fuel cladding in both benign and hostile environments as parameter(s) of significance in the PCI fuel failure phenomenon [21]. Based on these considerations, an empirical model for estimating the probability of a fuel failure in power increasing transients (PROFIT) was developed. 


\subsection{THE DATA BASE}

\subsection{INTRODUCTION}

The data used in the PROFIT model development were derived from two independent sources as follows:

1. PCI fuel failure observations from operating plants and one-of-a-kind irradiation experiments, and

2. plastic deformation and failure observations from mechanical and environmental effects experiments on Zircaloy and other metal alloys. The second source was considered to be pertinent because statistical studies [21] suggested that the operating variables $P, \Delta P, B u$, and some time parameter were inadequate to describe and define the PCI fuel failure phenomenon.

\subsection{FUEL FAILURE OBSERVATIONS}

Five fuel failure data sets were available for examination. These five data sets encompass fuels designed for duty in pressurized heavy water reactors (PHWRs), pressurized light water reactors (PWRs), and boiling light water reactors (BWRs). Many of the characteristic fuel design parameters, typical of the fueis from which most of the PCI fuel failure data were derived, are shown in Table 2.1. The common parameters reported for all five data sets are $P_{i}, P_{f}, \Delta P$, and $B u$.

Four of the five data sets, hereafter identified as Data Sets 1 through 4, were derived from commercial PHWRs and LWRs. Data Set 5 consists primarily 
TABLE 2.1. Fuel Design Parameters

\begin{tabular}{l} 
Parameters \\
\hline Cladding \\
Material \\
Outside diameter \\
Wall thickness \\
$\mathrm{R} / \mathrm{t}$
\end{tabular}

\begin{tabular}{|c|c|c|}
\hline \multicolumn{3}{|c|}{ Reactor Types } \\
\hline PHWR & PWR & $B W R$ \\
\hline Zircaloy-4 & Zirca Toy-4 & Zircaloy-2 \\
\hline 0.60 in. & $0.42 \mathrm{in}$. & 0.56 in. \\
\hline $0.015 \mathrm{in.}$ & $0.024 \mathrm{in.}$ & $0.037 \mathrm{in.}$ \\
\hline 20 & 9 & 7 \\
\hline
\end{tabular}

Fuel Pellet

Material

Density

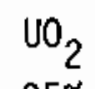

$\mathrm{UO}_{2}$

$95 \%$

$\mathrm{UO}_{2}$

Di ameters

$95 \%$
$0.56 \mathrm{in}$.

$0.36 \mathrm{in}$. $95 \%$

Fue 1 Rod

$\begin{array}{lccc}\text { Pellet-cladding gap } & 0.006 \mathrm{in} . & 0.007 \mathrm{in.} & 0.009 \mathrm{in} . \\ \text { Active fuel length } & 20 & 144 \mathrm{in} . & 144 \mathrm{in} . \\ \text { Pressurization } & (1 \mathrm{~atm}) & (1 \mathrm{~atm}) & (1 \mathrm{~atm})\end{array}$


of single fuel rod failures from one-of-a-kind experiments such as the Halden IFA-405 tests and other experimental irradiations [22-38].

These data sets did not include either qualitatively or quantitatively significant amounts of information relative to other operating variables such as power ramping $(\dot{P})$ and TTF. Nor did these data sets include significant amounts of information relative to fuel design variables such as:

- prepressurization

- pellet/cladding interfacial lubricants, surface coatings, and/or SCC inhibitors

- annular, chambered, dished, etc., fuel pellet geometries

- vibrationally compacted particle fuel.

In Data Set 1, a "dwell time" parameter was included. This "dwell time"* is the result of on-line refueling in pressure-tube type PHWRs. In on-line refueling, the fuel, which experiences $\Delta P$, is moved from its low $P_{j}$ position into the axial $P_{f}$ position within the pressure-tube fuel channel, where it "dwells" for approximately 18 minutes before it is moved to its final, lower power position. Power ramping rate information can be extracted from Data Set 1. The range of $\dot{P}$, however, is small and less than one order of magnitude. Very few $\Pi$ F and $\dot{P}$ data points were reported in Data Set 5 . The general distribution of the data in all fuel sets is shown in Figures 2.1 and 2.2. Considering the diversity in both fuel designs (see Table 2.1) and transient

\footnotetext{
*It has been inferred [12] that this "dwell time" is a manifestation of an "incubation time" for stress corrosion cracking by fission product iodine. It will be subsequently shown that any time lapse between the power ramp and failure is inversely proportional to the strain rate imposed on the fuel cladding by the transient differential thermal expansions of the fuel and cladding materials.
} 


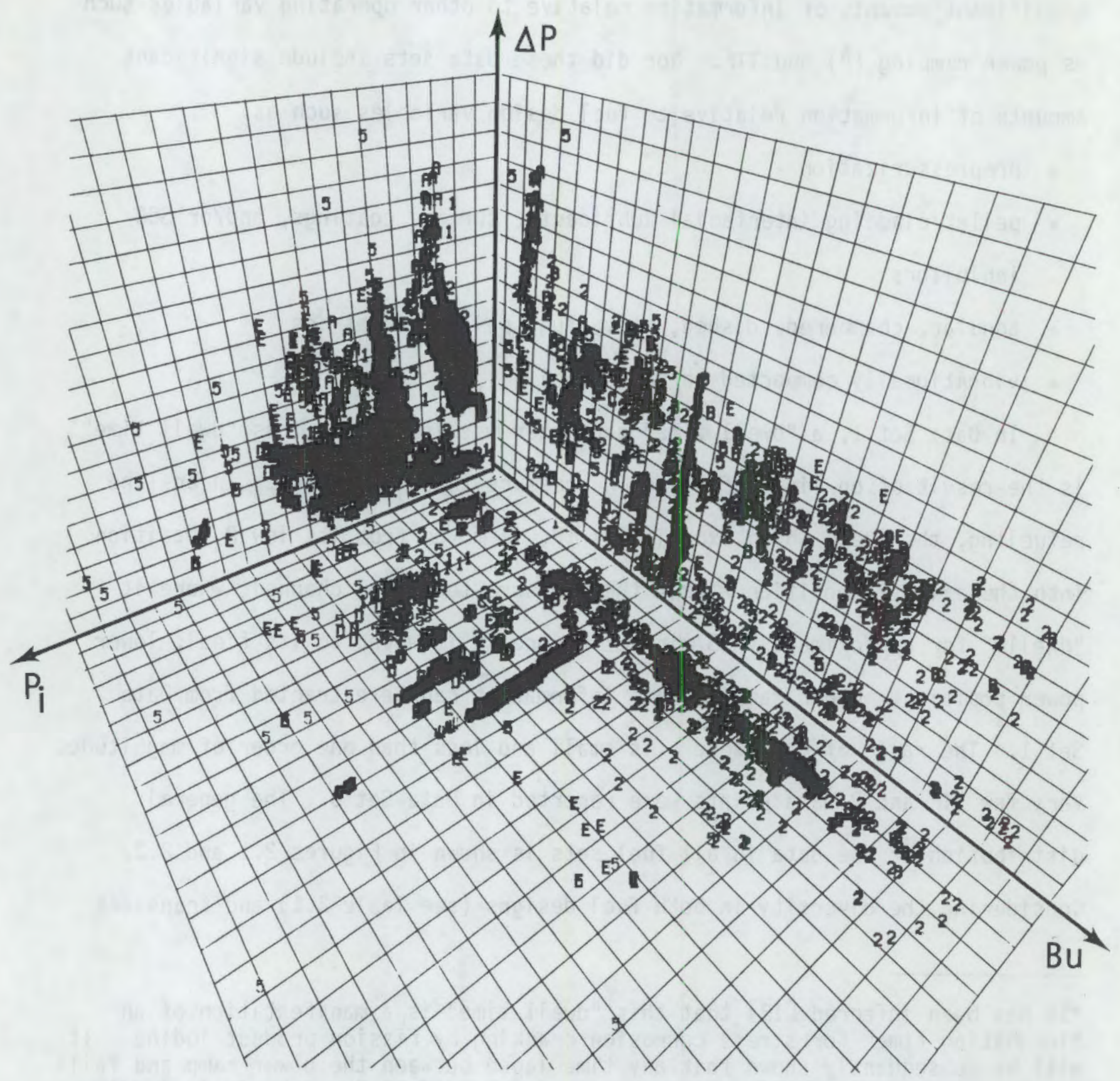

FIGURE 2.1. Data Sets 1 Through 5 Are Shown Collapsed on the $P_{i}$ versus $B u$, $P_{i}$ versus $\Delta P$, and $\Delta P$ versus $B u$ Phases. Non-failed and Failed Data are Identified by Number and Letter, Respectively. 


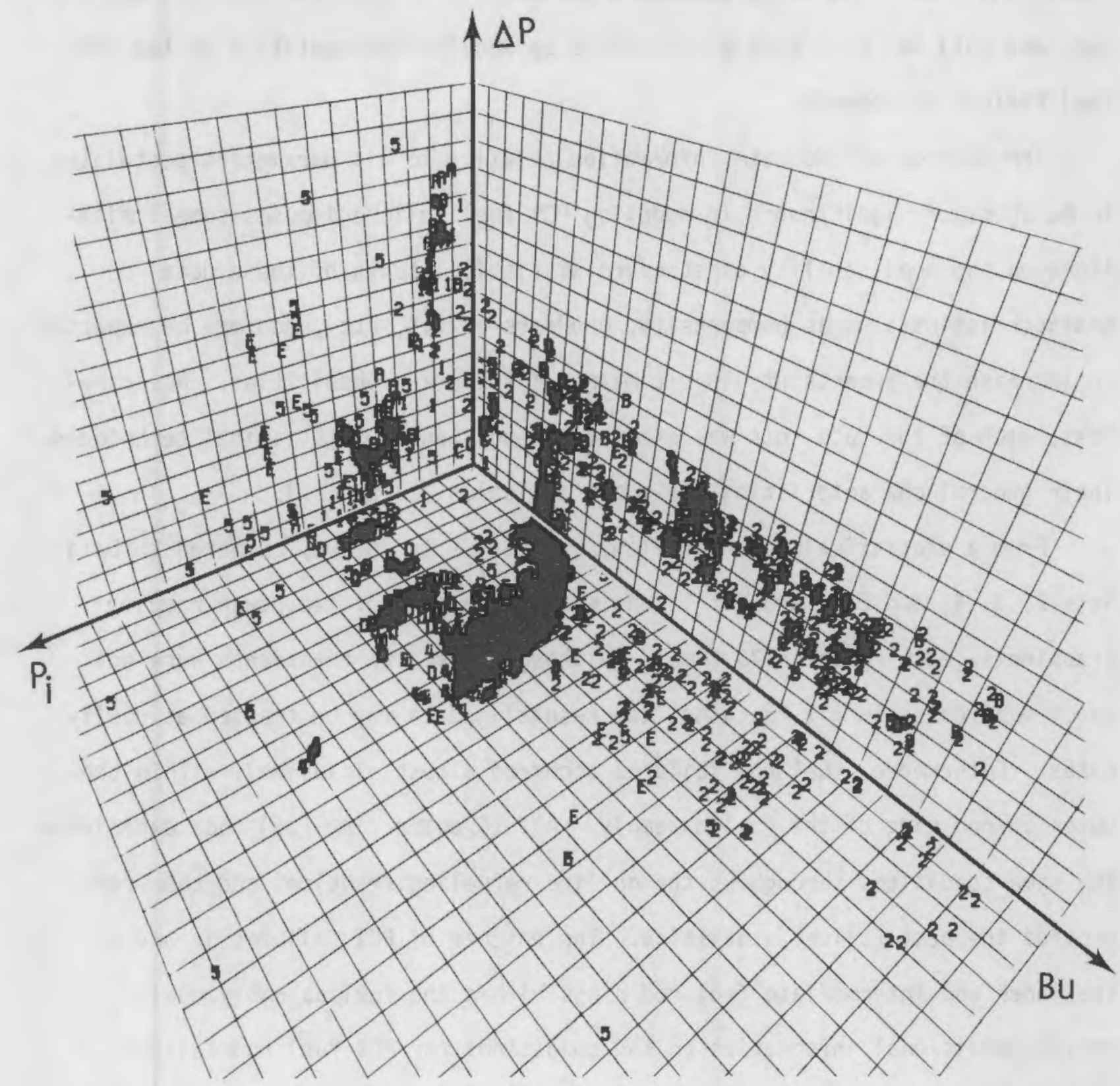

FIGURE 2.2. Data Sets 1 Through 5 Are Shown In An Isometric View Using the Parameter $\mathrm{P}_{i}, \Delta \mathrm{P}$, and $\mathrm{Bu}$. Non-failed and Failed Data are Identified by Number and Letter, Respectively. 
conditions from which these data were derived, it is doubtful that any one data set, and Data Set 5 in particular, would be wholly representative of the PCI fuel failure phenomenon.

The absence of adequate information relative to all parameters postulated to be of major significance in modeling PCI fuel failure imposes some limitations on the applicability of standard statistical tests of these data for characteristics such as homogeneity, goodness-of-fit, etc., and may be expected to increase the uncertainty in estimates of failure probabilities. Nevertheless, each of the data sets was examined using standard statistical techniques. The ir general characteristics are shown in Tables 2.2 and 2.3.

From a statistical point of view, Data Set 1 is unique, compared to Data Sets 2, 3, 4, and 5. Data Set 1 consists essentially of two power ramping transients, each repeated 23 times. Although these two transients were not exact duplicates in all 23 cases, the resulting data may be treated as duplicates. Futhermore, fuel rod failures occurred almost exclusively within the outer 16-rod ring of the fuel assembly. All 16 outer ring fuel rods experience the same conditions throughout the on-line refueling transient and therefore provide the best failure statistics. The absence of PCI failures in any of the inner and intermediate fuel rod rings within the fuel assembly could provide additional information on the conditions for PCI fuel rod failure. (This was not done in this study. Efforts are in progress to determine fuel rod failure statistics.)

Data Set 2 and, to a lesser extent, Data Sets 3 and 4 include some information on prior increases in fuel rod power. The significance of prior power ramp history relative to $\mathrm{PCI}$ fuel failure is uncertain. There are a few 
TABLE 2.2. Data Set Characteristics

\begin{tabular}{|c|c|c|c|c|}
\hline $\begin{array}{c}\text { Data Set } \\
\text { Identification }\end{array}$ & $\begin{array}{l}\text { Number of } \\
\text { Samples } \\
\text { In Set } \\
\end{array}$ & $\begin{array}{c}\text { Number of } \\
\text { Data Sets That } \\
\text { Failed }\end{array}$ & $\begin{array}{c}\text { Number of } \\
\text { Data Sets That } \\
\text { Did Not Fail }\end{array}$ & Failed Fraction \\
\hline 1 & 104 & 46 & 58 & 0.44 \\
\hline 2 & 572 & 67 & 505 & 0.12 \\
\hline 3 & 518 & 134 & 384 & 0.26 \\
\hline 4 & 481 & 101 & 380 & 0.21 \\
\hline 5 & 119 & 57 & 62 & 0.48 \\
\hline
\end{tabular}

TABLE 2.3. Numerical Characterization of Each Data Set

○

\begin{tabular}{|c|c|c|c|c|c|c|c|c|c|c|c|c|}
\hline \multirow{2}{*}{$\begin{array}{c}\text { Data Set } \\
\text { Identification } \\
\end{array}$} & \multicolumn{4}{|c|}{ Initial Power $\mathrm{kW} / \mathrm{ft}$} & \multicolumn{4}{|c|}{$\Delta$ Power $\mathrm{kW} / \mathrm{ft}$} & \multicolumn{4}{|c|}{ Burnup GWd/MTM } \\
\hline & $x$ & $\sigma$ & Min & Max & $x$ & $\sigma$ & Min & Max & $x$ & $\sigma$ & Min & Max \\
\hline 1 & 6.1 & 2.5 & 0.3 & 10.3 & 8.3 & 3.3 & 0.5 & 14.7 & 4.1 & 1.5 & 2 & 6.3 \\
\hline 2 & 2.9 & 1.1 & 0.8 & 8.0 & 5.5 & 2.8 & 0 & 11.5 & 15.4 & 5.1 & 1.4 & 25.5 \\
\hline 3 & 8.8 & 1.5 & 6.6 & 15.0 & 2.8 & 1.1 & 0.3 & 6.9 & 11.2 & 1.6 & 5.5 & 12.0 \\
\hline 4 & 6.2 & 0.8 & 2.9 & 9.4 & 4.2 & 2.1 & 1.2 & 10.5 & 11.7 & 0.6 & 7.7 & 11.8 \\
\hline 5 & 10.0 & 2.7 & 4.6 & 19.2 & 6.6 & 3.0 & 0.9 & 16.3 & 8.2 & 5.5 & 0.9 & 31.6 \\
\hline
\end{tabular}

where $X=$ mean value

$\sigma=$ standard deviation

Min = minimum value in the Data Set

Max = maximum value in the Data Set 
post-irradiation-examination (PIE) observations showing that part-through-wall cracking of the Zircaloy cladding or other undefined damage may occur as a result of a transient increase in fuel rod power [34]. These observations, however, are not sufficient to quantify the incidence of part-through-wall cracking of the Zircaloy cladding and the severity of the transient increase in power. Furthermore, our examination of Data Set 2 showed that repeated maximum increases in power rarely occurred within the same axial node of a fuel rod. If the Data Set 2 observations are generally typical, then prior power history would not be expected to be an operating parameter of first-order significance. For those cases where repeated transient increases in power may occur within the same axial fuel rod/assembly node, it may be possible to statistically treat such cases as separate and independent events, where in the failure probabilities for each of the events are combined.

In summary, the greatest uncertainties in these fuel failure observations appear to be:

1. the actual fuel rod power at which failure occurred;

2. the time, following the increase in power, at which failure occurred; and

3. the rate of the increase in power.

Although the apparent failure thresholds for LWR fuel appears to be lower than for CANDU fuel, these data do not show any obvious pattern or other direct link between the fuel design parameters represented in these data and the susceptibility to failure. 


\subsection{ZIRCALOY CLADDING DEFORMATION AND FAILURE CHARACTERISTICS}

There are at least two behavioral characteristics of Zircaloy that are very strain-rate dependent and appear to be of major significance to PCI fuel failures. These behavioral characteristics are:

1. strain-rate dependent plastic deformation as manifested in the drop-inload yielding, localized deformation, and wide variations in uniform and total elongation and reduction in area at failure; and

2. strain-rate dependent embrittlement as manifested in SCC and static fatigue.

There is no consensus as to which of these two strain-rate dependent behavioral characteristics dominate the Zircaloy fuel cladding failure. Based on the available but limited data, both strain-rate behavior characteristics appear to be of major importance and may even be synergistic.

\subsubsection{Strain-Rate Dependent Plastic Deformation in Zircaloy}

It is generally recognized that zirconium and some alloys display anomalous plastic deformation behavior within at least the $200^{\circ} \mathrm{C}<\mathrm{T}<400^{\circ} \mathrm{C}$ temperature range. The anomalies, of ten observed in connection with plastic tensile deformation, include:

1. localized yielding and strain softening as manifested by the drop-in-load yielding behavior,

2. an abrupt increase in the plastic flow stress accompanying an increase in strain rate when preceded by prestrain and interrupted loading at temperatures where dynamic strain aging may occur, and

3. a decrease in the strain energy absorption to failure with decreasing strain rate, and to a lesser extent, dependent on temperature. 
The third of the above anomalies has often been referred to as "slow strain-rate embrittlement" [39-42]. These anomalies are generally ascribed to dislocation-interstitial interactions, more commonly known as strain-aging. For Zircaloy, oxygen is generally considered to be the functional interstitial within principally the $200^{\circ} \mathrm{C}<\mathrm{T}<400^{\circ} \mathrm{C}$ temperature range [43-46].

Excepting strain-rate effects, the localized yielding anomaly has been fairly extensively investigated in uniaxial (plane stress) tensile tests on both irradiated [47] and unirradiated [48-52] Zircaloy. They are summarized as follows:

1. The sharpness of the yield point and the magnitude of the yield drop appear to increase with increasing temperature and decrease with increasing strain hardening. These effects appear to be dependent to some extent on the interstitial content.

2. Localized yielding does not require large prior plastic strains, nor is it attributable to deformation by twinning.

3. The yield drop appears to be inversely proportional to grain size, although a yield point has been observed in Zircaloy single crystals.

4. Irradiation appears to lower the temperatures at which localized yielding occurs.

Anisotropy effects on localized yielding have not been systematically explored. Considering the mechanisms postulated [48-51] to account for the localized yielding anomaly, a yield point is likely to be both more prevalent and pronounced in the hoop than in the radial or axial direction in zircaloy tubing. 
In PIE uniaxial (plane stress) tensile tests on rolled sheet, Bement [47] observed that the stress-strain behavior in the transverse direction was characterized by a sharp yield point and a single Luder's band,* where in all subsequent strain to failure was confined. In the longitudinal direction, however, the yield point at the same fluence was less pronounced and subsequent strain to failure was significantly less localized. This general stress-strain behavior was also observed in Hardy's [53] axial and transverse ring uniaxial (plane strain) tensile tests on Zircaloy tubing. There were slight differences in strain rates $\left(0.017 \mathrm{~min}^{-1}\right.$ and $0.05 \mathrm{~min}^{-1}$, respectively) in the axial and transverse ring tests. Hardy's investigations also included biaxial stress tests by internal pressurization of the Zircaloy fuel clad tubing. Except for the effective strengthening by the biaxial stress state, the general stress-strain (particularly the yield point behavior) does not appear to be significantly different from that in the transverse ring uniaxial tension tests. The effect of grain size on the stress-strain behavior was noted to be greater in the transverse ring uniaxial and internally pressurized biaxial stress tests than in the longitudinal uniaxial tension tests. There did not, however, appear to be any relative change in grain size effect by neutron irradiation.

Excepting strain-rate effects over a wide range of strain rates, the flow stress anomaly $(\Delta \sigma / \sigma)$ has been investigated in both uniaxial tensile and creep tests [48]. For unirradiated Zircaloy, determined from uniaxial tensile tests, the $\Delta \sigma / \sigma$ increases with aging time, aging stress, strain rate and temperature throughout about the $200^{\circ} \mathrm{C}<\mathrm{T}<450^{\circ} \mathrm{C}$ temperature range. The range of strain

*This is a manifestation of dislocation channeling. 
rates over which the $\Delta \sigma / \sigma$ anomaly was examined was relatively small, ranging from $0.0064 \mathrm{~min}^{-1}$ to $0.24 \mathrm{~min}^{-1}$. Based on PIE uniaxial (plane stress) tensile tests, Veevers et al. [45] concluded that the $\Delta \sigma / \sigma$ anomaly was reduced to insignificance after irradiation to a fluence ranging from 5.0 E 19 NVT to 1.0 E 19 NVT. As noted previously, radiation appears to lower the temperature at which the yield point, yield drop, and localized deformation occur. Based on this observation, is it not possible that radiation may cause a similar shift in the strain-aging temperature?

As determined in uniaxial tensile creep tests, the $\Delta \sigma / \sigma$ anomaly for unirradiated Zircaloy is manifested by significant reductions in creep rates which, with in the $200^{\circ} \mathrm{C}<\mathrm{T}<450^{\circ} \mathrm{C}$ temperature range, persist for substantial times (i.e., $\gg 1000 \mathrm{hr}$ ) [54-56]. The time the reduced creep rates persist appears to be inversely proportional to temperature. The effect of neutron irradiation, as determined from influx uniaxial tensile creep tests, is to markedly reduce the time ( 0 to $10 \mathrm{hr}$ ) during which the creep rates are reduced [55].

The effect of interstitial content and strain rate on the tensile and SEAF properties has only been explored to a limited extent in Zircaloy [41-44] and a few other reactive metals $[40,41,57]$. Figure 2.3 shows the independent effects of the interstitial (hydrogen) content and strain rate on the reduction in cross-sectional area at failure as a function of temperature for an alpha phase Ti alloy [57]. For high purity niobium, Figure 2.4 shows the virtual absence of any strain rate and temperature effect when the interstitial (hydrogen) is absent and the very strong dependence of the reduction in cross-sectional area at failure on strain rate and temperature for even modest interstitial (hydrogen) content [40]. Figure 2.5 shows the effect of strain rate and temperature 


\section{EFFECT OF HYDROGEN CONTENT ON HYDROGEN EMBRITTLEMENT}

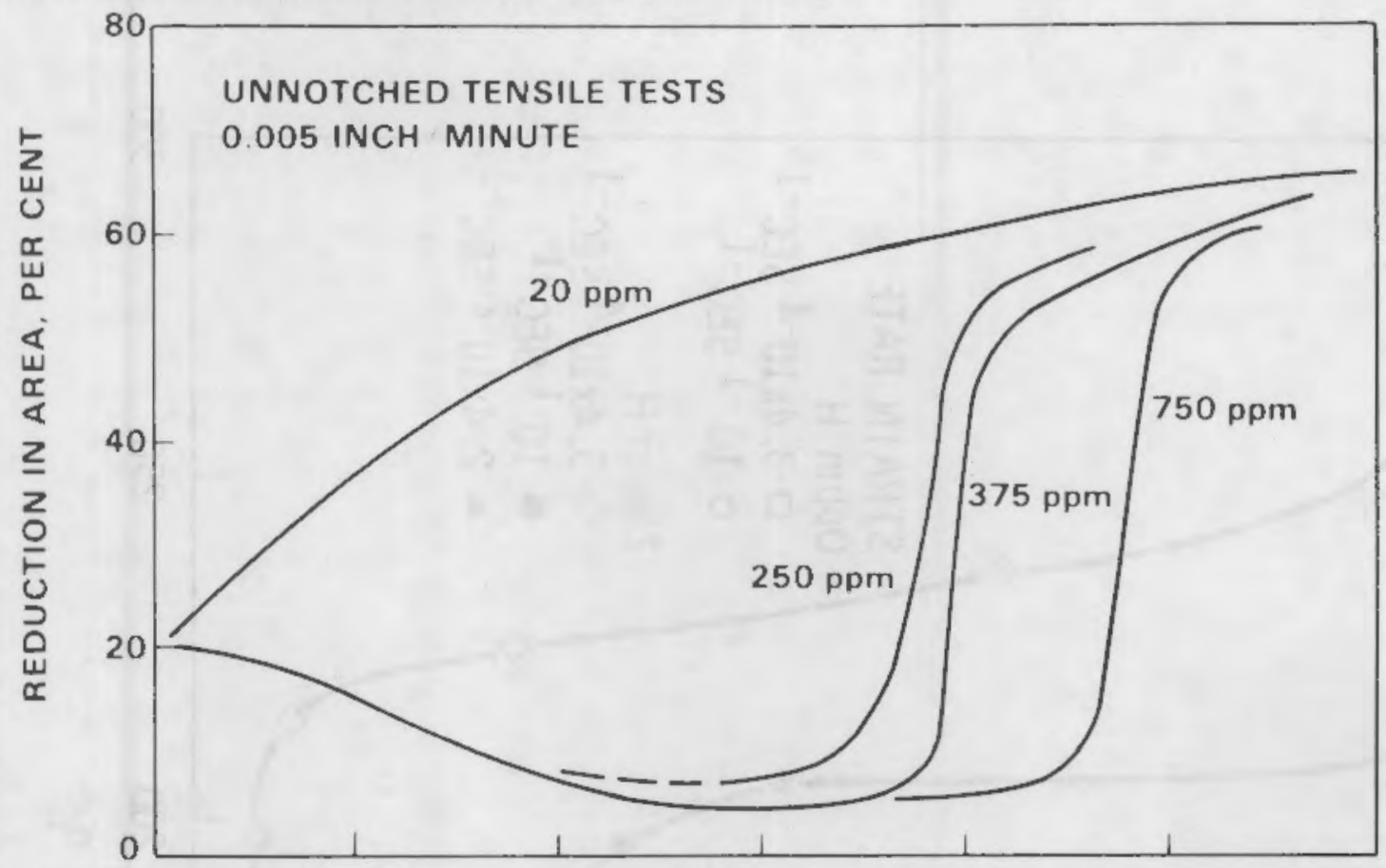

EFFECT OF LOADING RATE ON HYDROGEN EMBRITTLEMENT

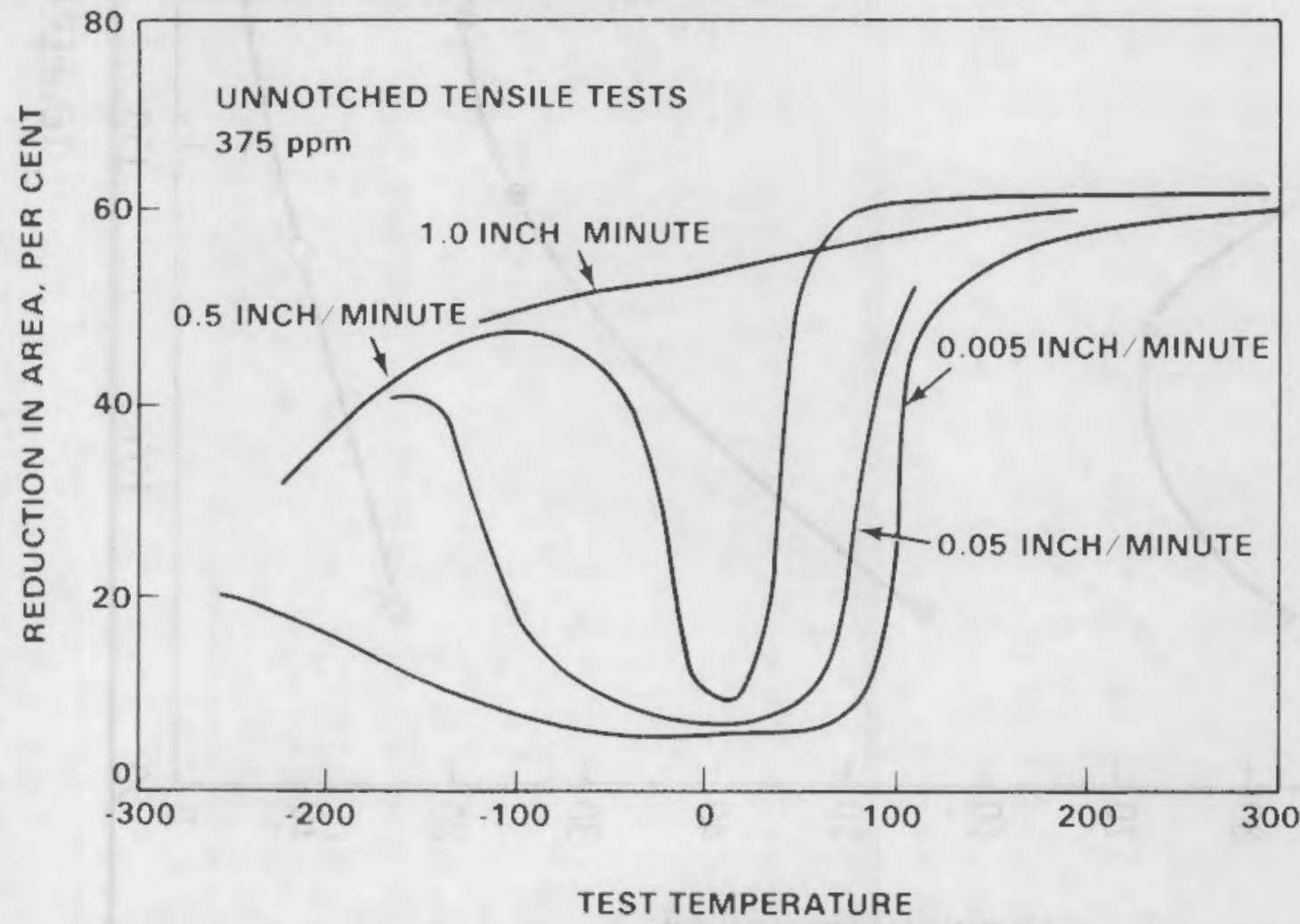

FIGURE 2.3. Effects of Hydrogen Content, Strain Rate, and Temperature on the Tensile Ductility of a Typical $\alpha / \beta$ Titanium Alloy. From "The Hydrogen Embrittlement of Titanium Alloys," D. N. Williams, The Journal of the Institute of Metals, Vol. $91,1962-63[57]$. 


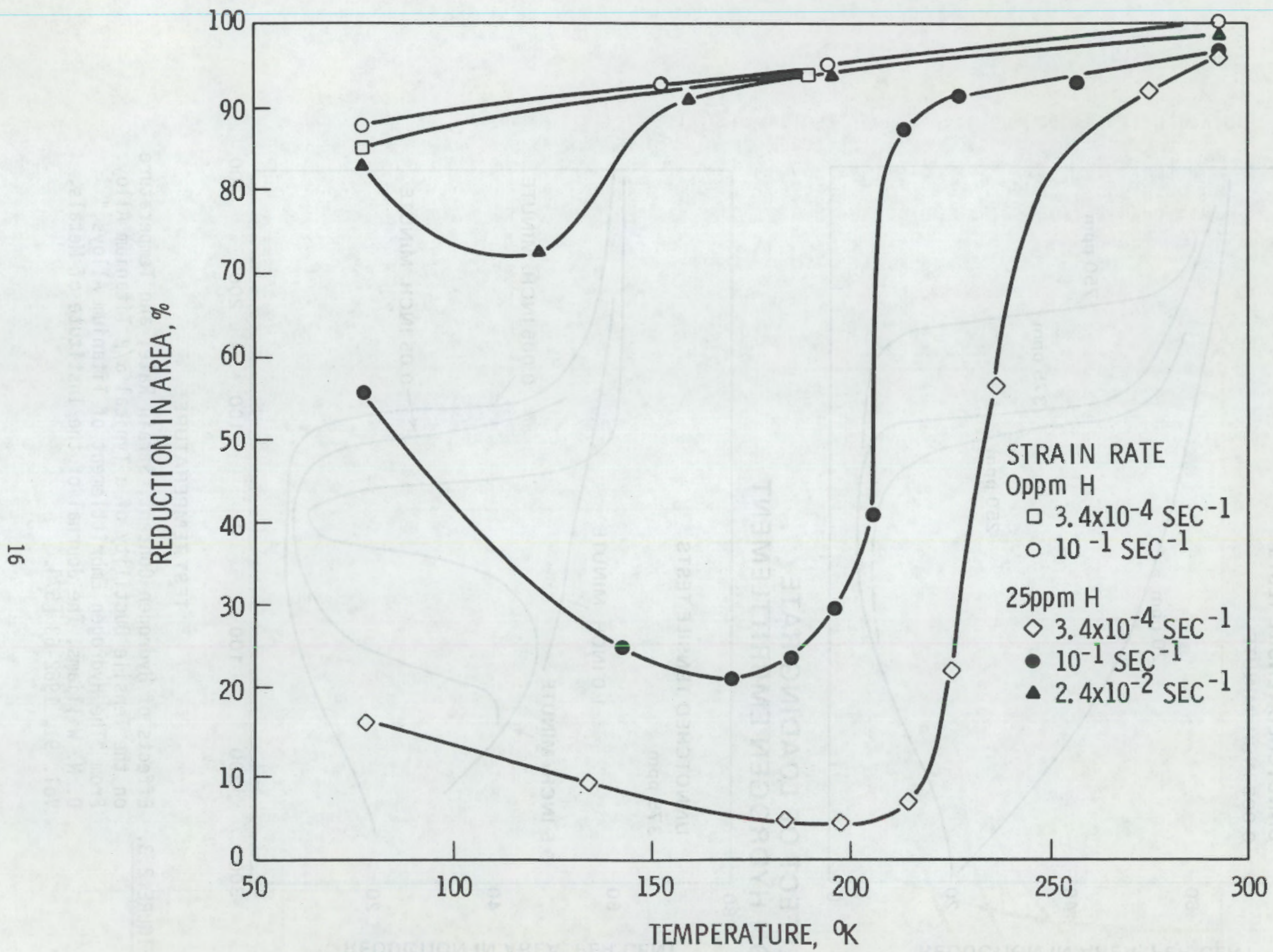

FIGURE 2.4. Hydrogen Embrittlement of Niobium as Shown by Curves of Reduction in Area Versus Testing Temperature. Reprinted by permission of R. E. Reed-Hill, University of Florida, Gainesville, Florida, from "Slow Strain-Rate Embrittlement in Metals," J. R. Donoso, A. T. Santhanam and Prof. R. E. Reed-Hi11, Second International Conference on Mechanical Behavior of Materials, 1976 [41]. 


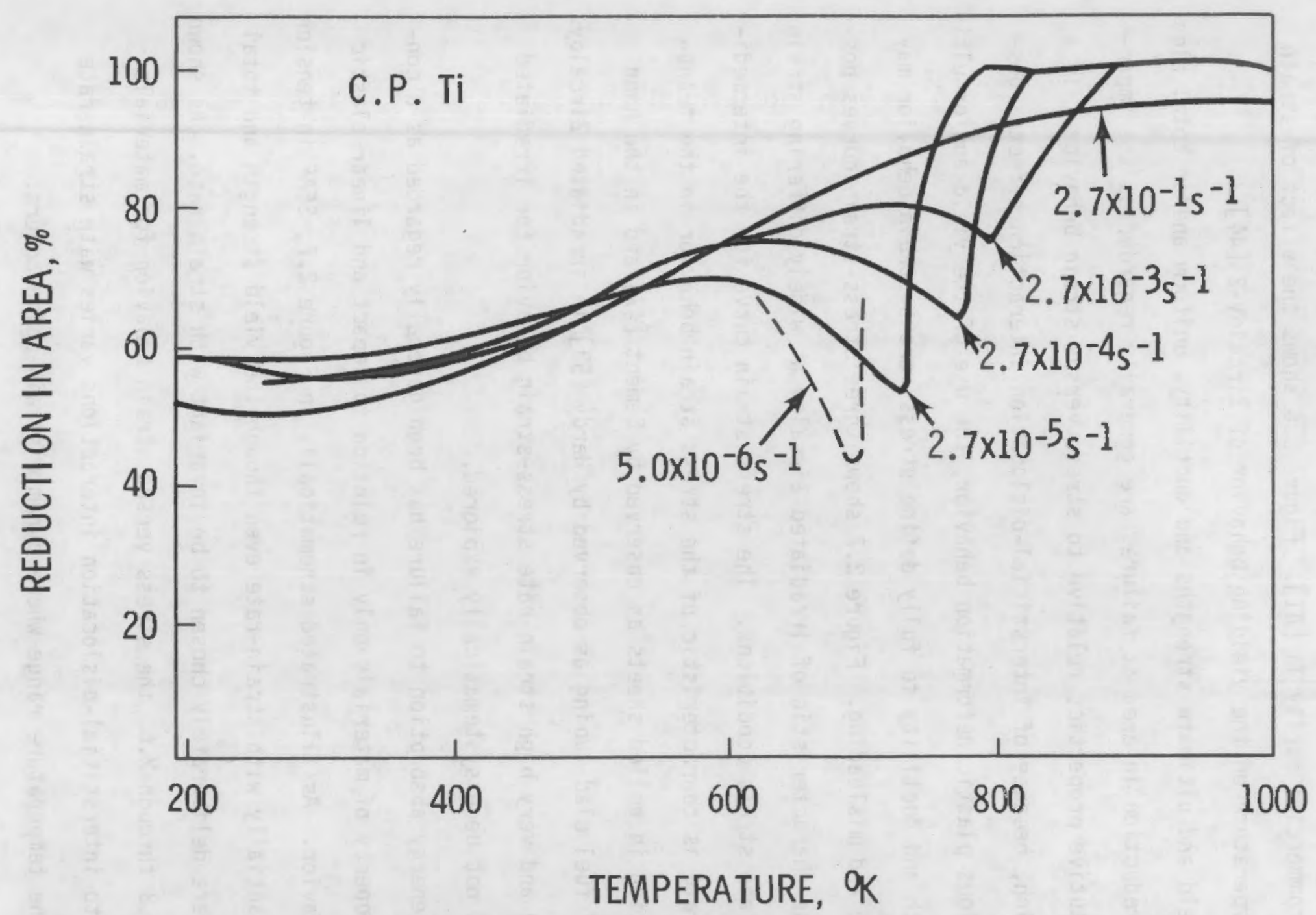

FIGURE 2.5. The Strain-Rate Dependence of the Reduction-in-Area Versus Testing Temperature Curves of a Commercial Purity Titanium Containing $0.4 \mathrm{a} / 0$ 0xygen. Reprinted by permission of R. E. Reed-Hill, University of Florida, Gainesville, Florida, from "Slow Strain-Rate Embrittlement in Metals," J. R. Donoso, A. T. Santhanam and Prof. R. E. Reed-Hill, Second International Conference on Mechanical Behavior of Materials, 1976 [41]. 
on the reduction in cross-sectional area at failure when oxygen is the interstitial in commercial purity $\mathrm{Ti}$ [41]. Figure 2.6 shows the effect of strain rate and temperature on the yielding behavior of Zircaloy-2 [44].

The yield and ultimate strengths and ductility, uniform and/or total elongation and reduction in area at failure, are generally regarded as the important constitutive properties relative to stress versus strain behavior. In a material which, because of interstitial-dislocation interaction effects, displays anomalous plastic deformation behavior, the use of the yield and/or ultimate strength and ductility to fully define stress versus strain behavior may be deceptive and misleading. Figure 2.7 shows three stress-strain curves postulated to be characteristic of irradiated Zircaloy at widely differing strain rates and $\mathrm{plane}$ stress conditions. The stress-strain curve for the intermediate strain rate is characteristic of the stress strain behavior in the transverse direction in rolled sheets as observed by Bement [47] and in the hoop direction of fuel clad tubing as observed by Hardy [53] in irradiated Zircaloy. The very low and very high strain-rate stress-strain behavior for irradiated Zircaloy has not been systematically explored.

Strain energy absorption to failure has been generally regarded as a constitutive property of materials only in relation to impact and linear elastic fracture behavior. As illustrated schematically in Figure 2.7, SEAF in tension varies substantially with strain-rate even though the yield strength and total elongation were deliberately chosen to be invariant with strain-rate. As shown in Figures 2.3 through 2.6, the stress versus strain behavior for materials susceptible to interstitial-dislocation interactions varies with strain-rate throughout the temperature range where dynamic strain aging occurs. 


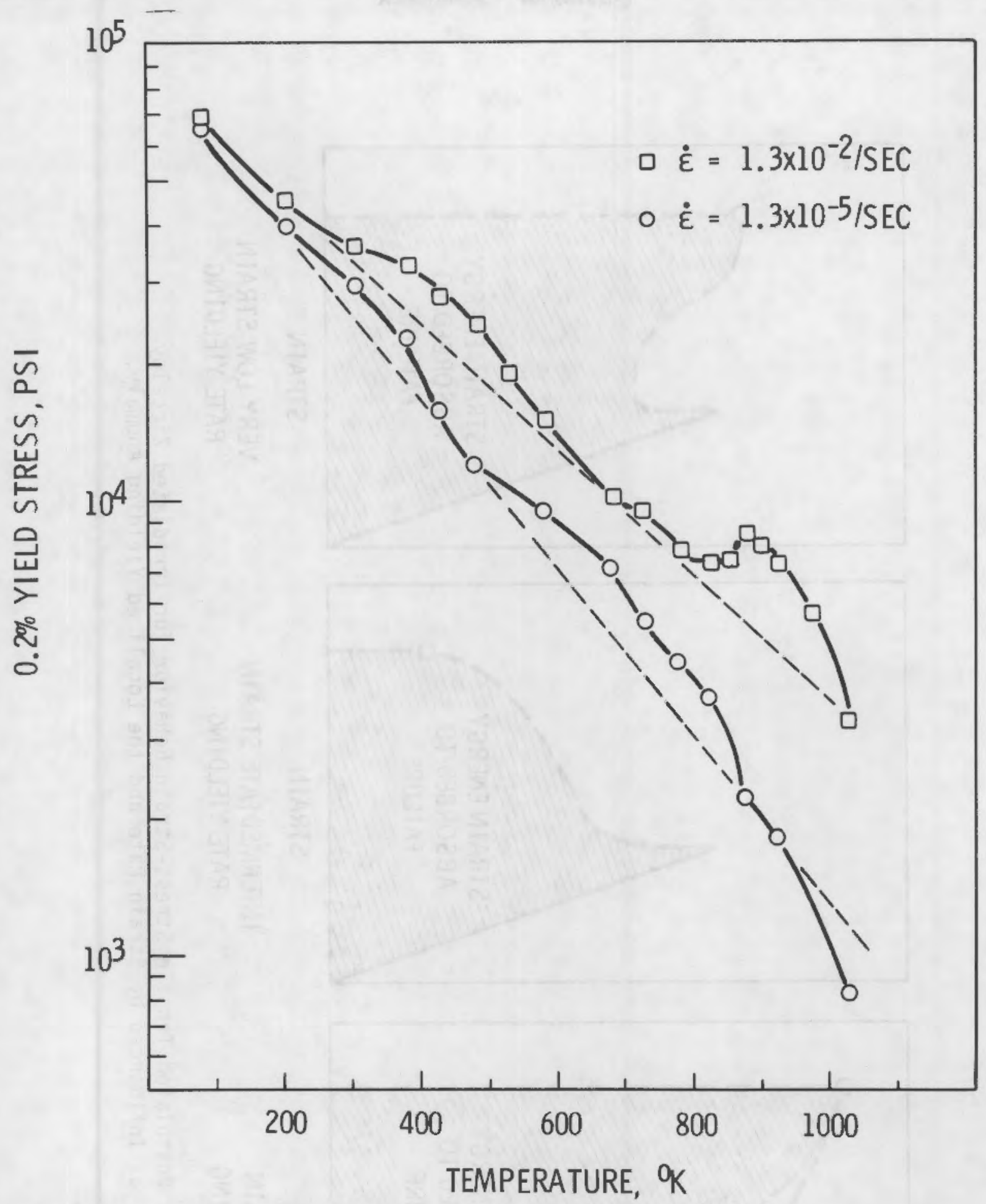

FIGURE 2.6. When a More Extensive Set of Data is Used, a Log Yield Stress-Temperature Plot Shows Regions in Which the Curves Deviate from Linearity. In These Regions Strain Aging Phenomena are Observed. Curves Corresponding to Zirconium Specimens Deformed at Two Strain Rates are Shown. Reprinted by permission of R. E. Reed-Hill, University of Florida, Gainesville, Florida, and the Metallurgical Society of AIME, 420 Commonwealth Drive, Warrendale, Pennsylvania, 15086. Copyright ASM and The Metallurgical Society of the AIME, 1970. From Metallurgical Transactions, VI, 1970 [44]. 


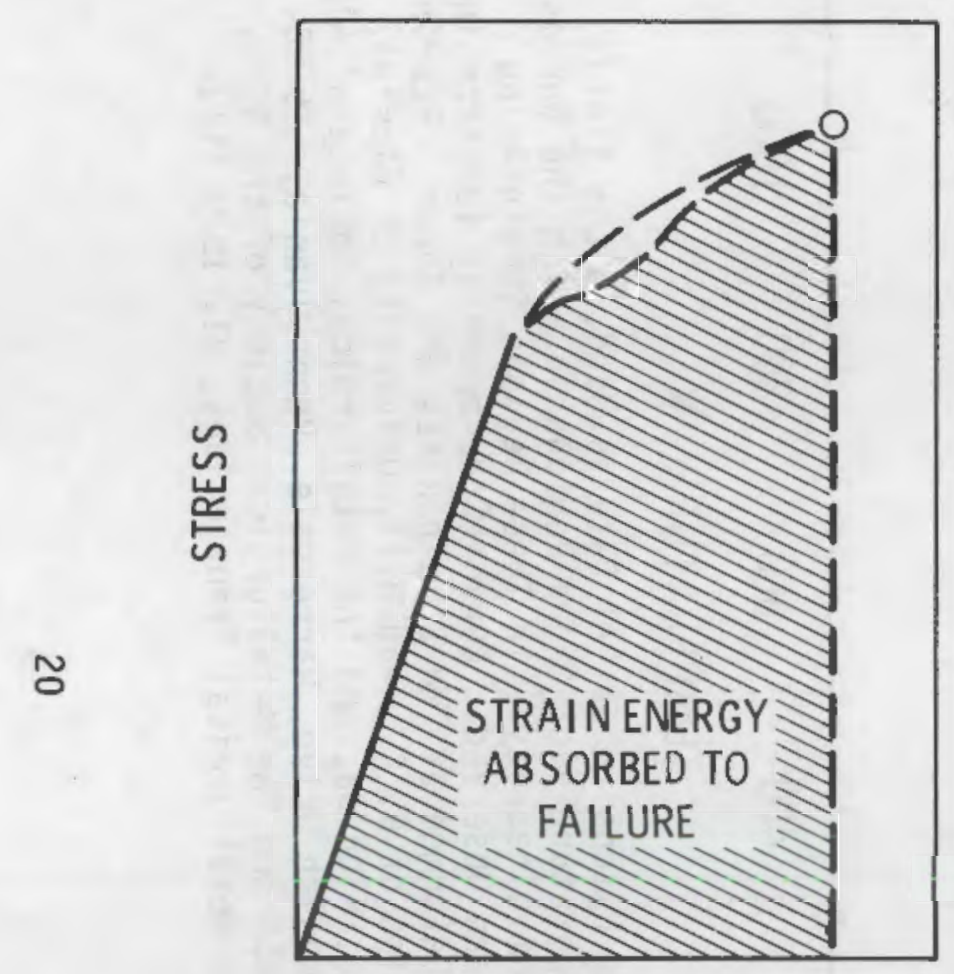

STRAIN

HIGH STRAIN RATE YIELDING

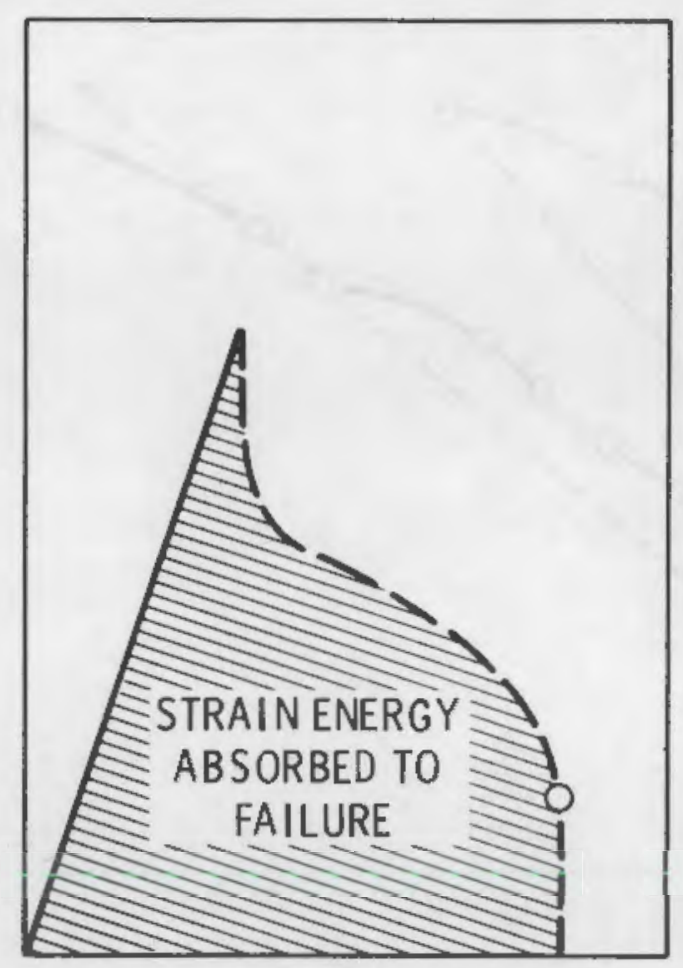

STRAIN

INTERMEDIATE STRAIN RATE YIELDING

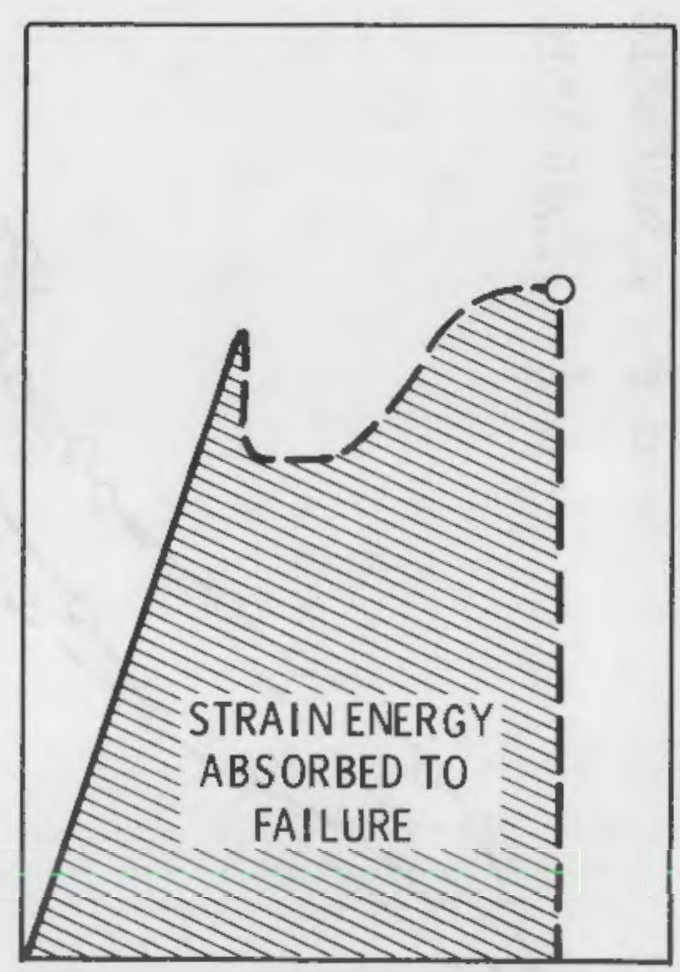

STRAIN

VERY LOW STRAIN RATE YIELDING

FIGURE 2.7. Postulated Tensile Stress-Strain Behavior for Irradiated Zircaloy as Influenced by Strain Rate and the Localized Yielding Anomaly. 
The effect of strain rate on the tensile stress versus strain behavior of Zircaloy was investigated to a limited extent by Lee [58]. All tests were conducted at $350^{\circ} \mathrm{C}$. All tensile coupons were taken from the transverse direction of rolled sheet. The effect of strain rate on the tensile stress versus strain behavior of irradiated Zircaloy was investigated to a lesser extent by Azzarto et al. [59]. The PIE tensile tests were conducted at $282^{\circ} \mathrm{C}$. Irradiation exposures range from 6.0E20 NVT to 9.4E20 NVT. The results of these two stressstrain behavior investigations are shown in Figure 2.8, where SEAF relative to the minimum SEAF in each data set is plotted as a function of strain rate. As a matter of interest, SEAF for the irradiated condition is about $1 / 6$ to $1 / 7$ of that for the unirradiated conditions at all strain rates. This difference, however, partially represents the test temperature difference, as well as the irradiation effect on the SEAF.

These experimental observations--as we 11 as those by Bement [47] and Hardy [53] on irradiated Zircaloy, of a yield point, yield drop, and localized strain to failure--strongly suggest that this stress-strain anomaly is of major importance in the PCI fuel failure phenomenon. The occurrence of a yield point and yield drop as a manifestation of dislocation channeling constitutes a mechanical instability where the external loading and/or displacement necessary to sustain plastic deformation in the dislocation cleared channels is less than that required to initiate yielding. Under this condition, further straining will occur in the dislocation cleared channels, in the absence of any change in the external loading and/or displacement, until the difference between the strain energy required for the initial yielding and that required to sustain plastic deformation in the dislocation cleared channels is dissipated in 


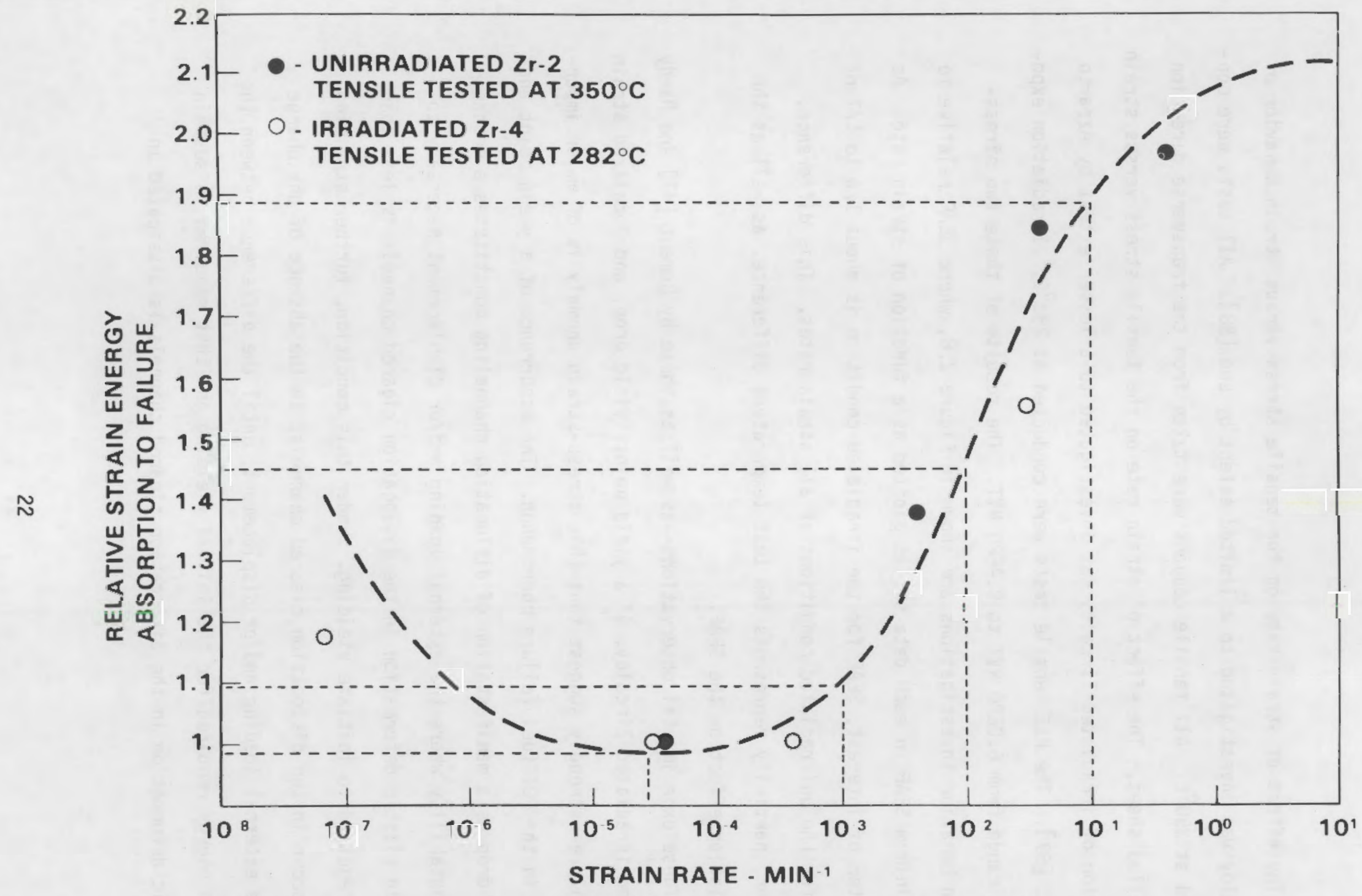

FIGURE 2.8. The Effect of Strain Rate on the Relative Strain Energy Absorption to Failure as Determined for Available Uniaxial Tensile Data. 
plastic deformation. When this concept is applied to a fuel rod, it must be recognized that the strain energy differential, as just defined, will be in direct proportion to the ratio of the cross-sectional area of the fuel rod and the localized yielding zone(s) in the Zircaloy cladding. These considerations suggest that the occurrence of a yield point and yield drop in the zircaloy cladding of a fuel rod provides a strain energy differential which is at least potentially greater than can be dissipated in localized plastic flow without incurring failure.

\subsubsection{Strain-Rate Dependent SCC Embrittlement in Zircaloy}

One view is that the dominant failure mechanism in the PCI fuel failure phenomenon is SCC and/or liquid/vapor metal embrittlement (L/MME)* by fisson products, such as iodine, cadmium, etc., which may be more or less promptly released from the fuel during a power transient. Moreover, this viewpoint generally holds that a critical threshold stress within the Zircaloy cladding must exist for failure by the SCC mechanism. Considerable experimental effort has been expended in an attempt to establish the existence of and quantify the critical threshold stress for SCC. There is, however, a growing body of experimental data showing that strain rate and, perhaps, strain are key parameters in the SCC phenomenon [59-64].

Parkins [60] (See Figure 2.9) and others [61-64] have shown that the susceptibility of metal alloys to SCC, as evidenced by a reduction in the tensile strength or fracture ductility, is, among other factors, strongly and directly related to the strain rate imposed on the SCC test coupon. Scully et a1. [63]

*From this point on, no further distinction is made between embrittlement by SCC or L/VME. 


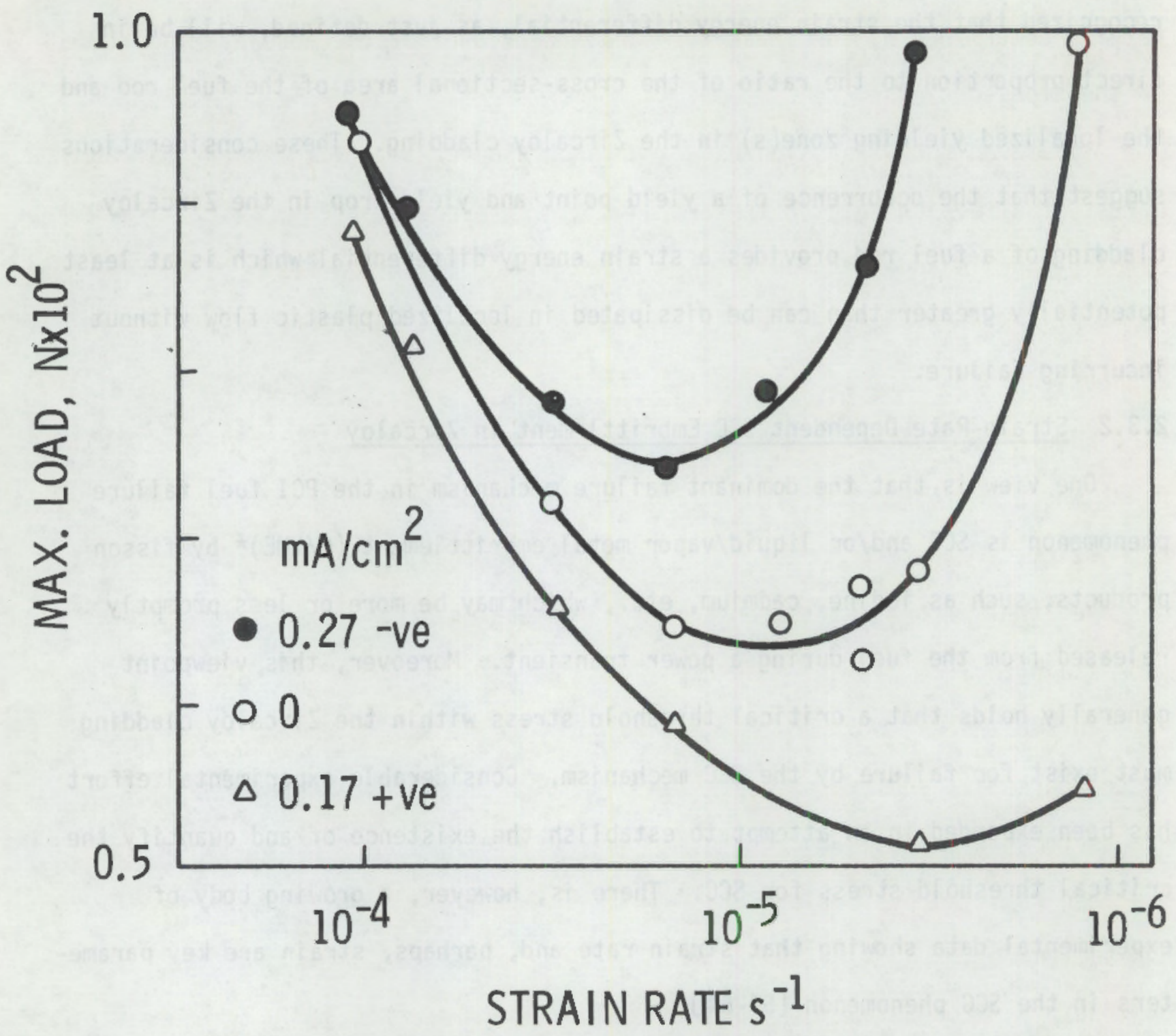

FIGURE 2.9. Effects of Various Strain Rates on the Cracking Response of a Mg-Al Alloy in a $\mathrm{CrO}_{4}-\mathrm{Cl}$ Solution at Various Applied Current Densities. Reprinted, with permission, from the American Society for Testing and Materials, 1916 Race Street, Philadelphia, PA, 19103. Copyright ASTM STP 665, 1979 [60]. 
have shown experimentally in SCC tests on notch-defected coupons that the SCC rate is determined by the crack tip strain rate and not the absolute magnitude of the imposed stress.

Simulated fuel expansion experiments by wood et al. [10] crudely show the effect of straining rate on the averaged circumferential strain at failure in Zircaloy fuel cladding in an iodine environment. In $I_{2}$ SCC tests on unirradiated Zircaloy, Peehs et al. [65] observed a minimum in the relative uniform elongation at a critical strain rate. At either faster or slower strain rates (see Figure 2.10), the effective aggressiveness of the iodine diminishes to the point where the effect of strain rate on the reduction in relative uniform elongation is directly proportional to the iodine concentration. Coffin [66] observed that increasing temperature and decreasing strain rate enhance the embrittling effect of iodine on Zircaloy.

In smooth bar specimens under tension, Parkins [60] observed that failure in an aggressive environment is preceded by the appearance of many surface cracks for all metal alloy systems investigated. Similar cracking behavior has been reported by Tomalin [67], Lee and Adamson [68] with Zircaloy in iodine, and by Grubb [16] in liquid cadmium and cadmium-cesium mixtures. By contrast, a notch-defected coupon was always observed to fail by cracking from the notch root $[60,63]$. Cubicciotti et al. [18] observed this behavior with tubing notched in the ID surface and tested under tension by internal pressurization with helium and iodine mixtures. Coffin [66] observed that microcracking was not observed at strains below about 0.6 to $0.7 \%$. Zebroski and Roberts [70] have reported that the minimum strain for cracking the oxide surface film was about $0.4 \%$. Cubicciotti et al. [18] performed experiments where 


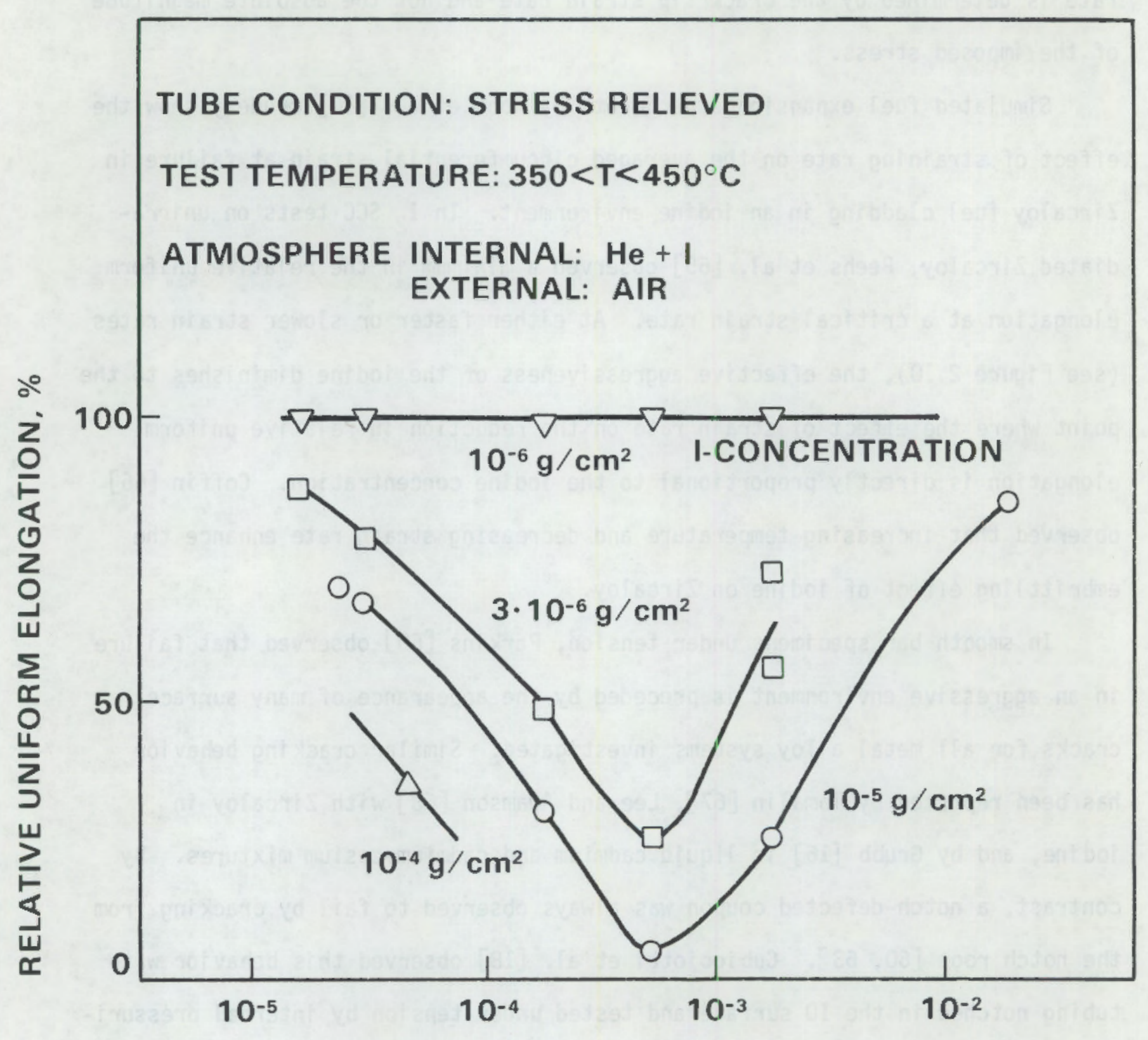

\section{DEFORMATION RATE, 1 /H}

FIGURE 2.10. Dependence of the Relative Uniform Elongation on Deformation Rate and I-Concentration. Reprinted, with permission, from the American Society for Testing and Materials, 1916 Race Street, Philadelphia, PA 19103. Copyright ASTM STP 681, 1979 [65]. 
the cracked oxide film was removed by ion milling to reveal the microcracking in the metal substrate. The microcracking in the metal substrate was observed only at second phase particles. It apparently was not determined whether the microcracking developed from fracturing of the second phase particle itself or as decohesion of the second phase particle from the surrounding metal matrix. In any case, plastic deformation, as manifested by slip, appears to be necessary to initiate microcracking by either process. In these experiments, there were no measurements of the strain at which microcracking was observed, although the strain in the coupon ranged from about 1 to $6 \%$.

An examination of fixed load SCC test data $[13-15,18]$ reveals that the stress and temperature conditions were conducive to deformation by creep. In those SCC experiments where measurements were obtained, the reported deformations at failure ranged to about $3 \%[13,14]$. There is a general consensus that SCC, in fixed load tests, must be preceded by some plastic deformation. Employing both constant extension rate and fixed load tests, Une [70] clearly demonstrated the fundamental importance of strain rate in iodine embrittlement. Figure 2.11 shows these experimental results and comparisons with fixed load SCC results. Figure 2.11 further shows the existence of an inverse proportionality between strain rate in constant extension rate SCC tests and TTF in fixed load SCC tests. Buhl [71], Kimm and Wilde [72] and Andrew et al. [73] have obtained similiar comparisons between constant strain rate and fixed load SCC behavior in other metals. Buhl's [71] investigations are of some further interest because SEAF was used as the material parameter in characterizing the susceptibility of materials to SCC. 

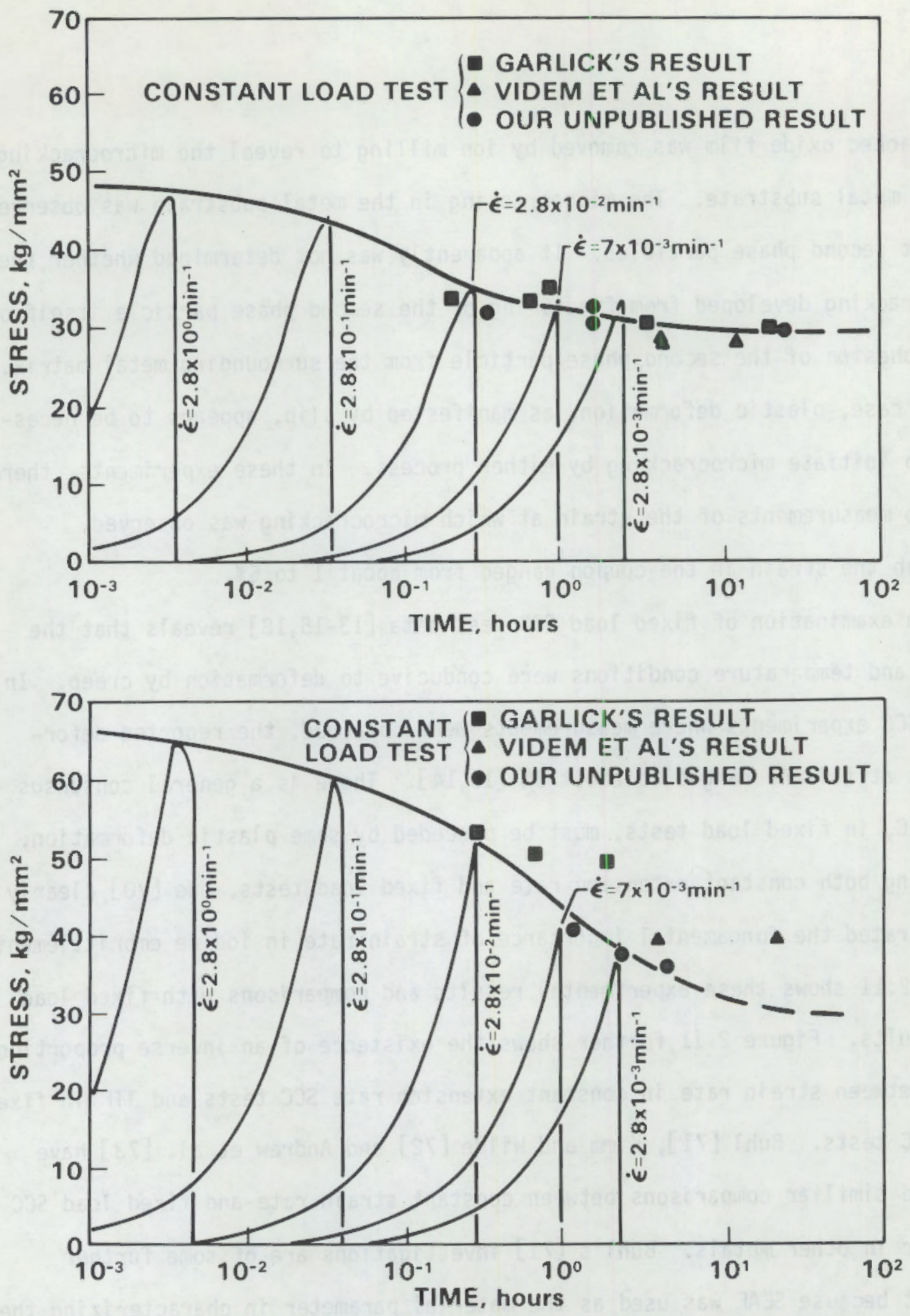

FIGURE 2.11. Stress-Time Curves in Constant Extension Rate Test for Stress-Relieved Material (upper) and Recrystallized Material (lower). Reprinted by permission of the American Nuclear Society, Inc., La Grange Park, I1, Copyright ANS, 1979, From Proceedings of ANS Topical Meeting on Light Water Reactor Fuel Performance, Portland, OR, April 29-May, 1979 [70]. 


\subsubsection{Sumary of Strain-Rate Effects}

The experimental observations previously discussed begin to show the importance of strain and strain rate on the tensile load carrying characteristics of interstitial-dislocation interaction sensitive materials in either aggressive or non-aggressive environments. As shown in Figure 2.8 for Zircaloy in both the non-irradiated and irradiated condition and by Buhl [71] in his SCC investigations of other materials, SEAF appears to be a constitutive material property that can accommodate the effects of strain rate and temperature on all tensile (i.e., yield and ultimate strength, uniform and total elongation, reduction in cross-sectional area at failure, TTF, etc.) characteristics of interstitial-dislocation interaction sensitive materials in either aggressive or benign environments. The effect of strain rate for both aggressive and benign environmental conditions at constant temperature is shown schematically in Figure 2.12. Curve 1 is characteristic of the load carrying and/or plastic deformation behavior of interstitial-dislocation interaction sensitive materials in benign environments normalized to the tensile characteristics in air, where an air environment, at temperatures of interest, is assumed to be nonaggressive. Under these conditions, Curve 1 is a straight line with zero slope. Curve 2 is considered to be most characteristic of the so-called "slow strain-rate embrittlement" behavior of interstitial-dislocation interaction sensitive materials when hydrogen is the interstitial element. Curve 3 is considered to be most characteristic of the behavior of interstitialdislocation interaction sensitive materials in an aggressive (SCC) environment. Indeed, there is significant similarity between Curve 3 and those developed by Peehs et al. [65] for Zircaloy tubing (see Figure 2.10) and Parkins [60] (see 


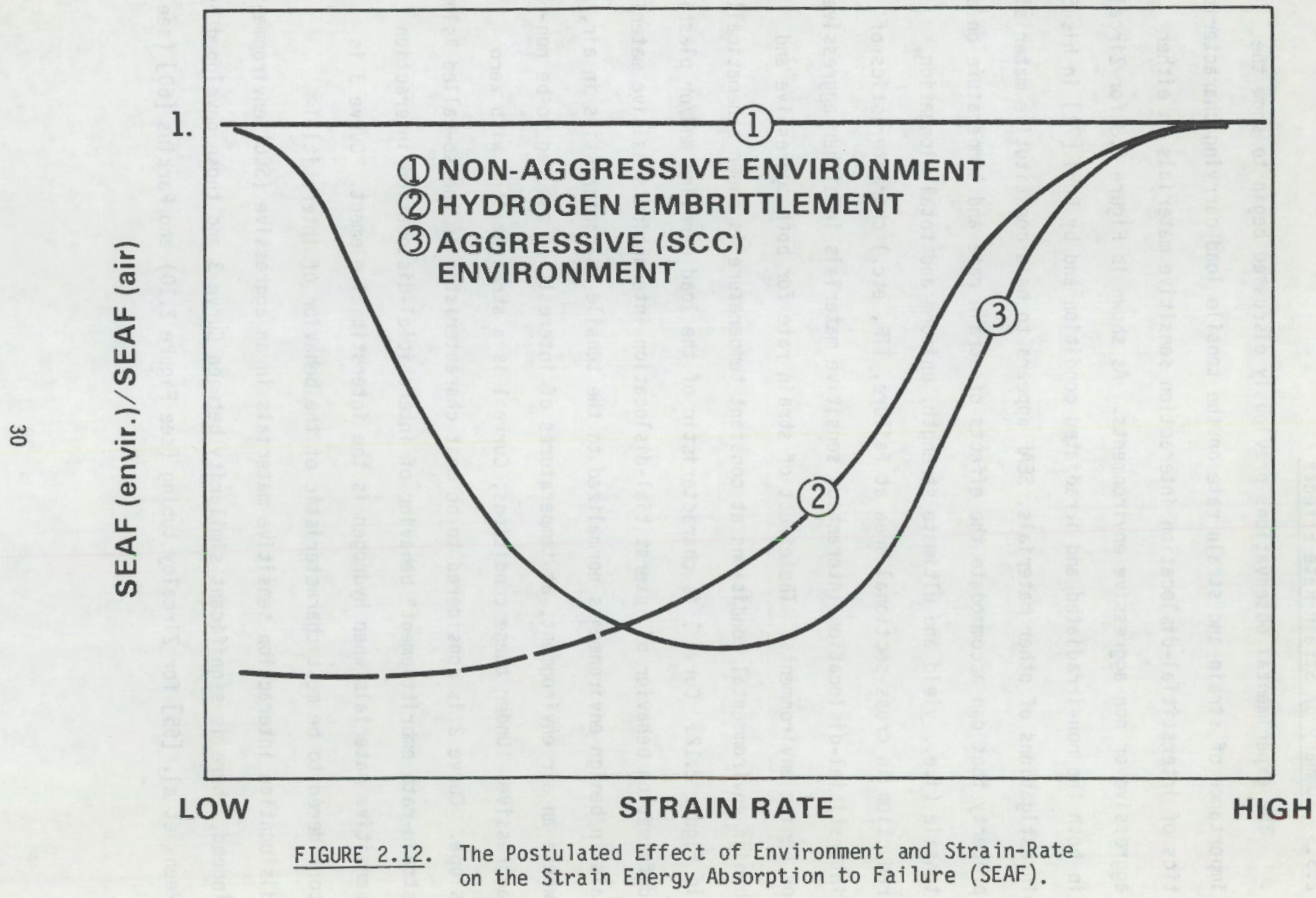


Figure 2.9) and others [61-64] for other interstitial-dis location interaction sensitive materials in aggressive (SCC) environments. However, as shown in Figure 2.8, a similiar pattern was developed for Zircaloy in both the nonirradiated [58] and irradiated [59] condition. Other interstitial-dislocation interaction sensitive materials $[40,41,57]$ tested in a benign environment show similar patterns in stress versus strain behavior (see Figures 2.3 through 2.6). Data obtained by Coffin [66], Tomalin [67], Lee and Adamson [68], and Grubb and Morgan [16] leave little doubt that SEAF is also diminished when tested in an aggressive $\left(I_{2} S C C\right.$ or $\left.L / M M E\right)$ environment. These data, however, are inadequate to quantify the effect over any strain-rate range of interest. These data also suggest that SEAF, as a function of environment and strain rate, may also be sensitive to the state of strain and applied stress. Based on all of the foregoing, it is postulated that Curve 3 is far more uniquely characteristic of a material's sensitivity to the interstitial-dislocation interaction(s) than it's susceptibility to SCC. Alternatively, one might postulate that a material's sensitivity to SCC may be strongly dependent upon it's sensitivity to the interstitial-dis location interaction(s). 



\subsection{THE PROFIT FUEL FAILURE MODEL}

\subsection{MODELING CONSIDERATIONS}

PCI fuel failures have been modeled empirically $[21,22]$ in terms of operating parameters such as $P_{f}, \Delta P, B u$, and the "dwell time" at $P_{f}$, the delay between the transient and failure. Exploratory and experimental efforts have been undertaken to identify and quantify mechanism(s) for PCI fuel failures. These efforts, as yet, have not been fully successful. There appears however, to be a general consensus that thermo-mechanical and thermo-chemical mechanisms play key roles in PCI fuel failure.

It has been postulated that the operating parameters available for this study, which have been used in empirical fuel failure modeling, are the corollary of certain thermo-mechanical and thermo-chemical fuel behavior mechanisms [74]. The postulated mechanistic corollaries are as follows:

1. The mechanistic corollary to $P_{f}$ is the fuel temperature for relatively prompt fission product release from the fuel. This temperature appears to be the temperature at which thermally activated solid state reactions, diffusional processes, knockout-recoil mechanisms, etc., begin to occur at significant rates. The fission products of concern appear to be those that are chemically aggressive to the Zircaloy cladding (e.g., $I_{2}, C d$, etc.). These considerations imply that, whenever the fuel rod/assembly power $\left(P_{f}\right)$ is used as one of the PCI fuel failure modeling parameters, the values chosen for $P_{f}$ must correspond to the fuel temperature. For 
example, in very fast transients due to a sudden and substantial reactivity insertion, there is likely to be a significant mismatch between the heat generation rate and the actual temperatures corresponding to an equilibrium temperature within the fuel. It should also be noted that $P_{f}$ is merely the sum of $P_{i}$ and $\Delta P$ in the fuel rod/assembly power.

2. The mechanistic corollary to $\Delta P$ in fuel rod/assembly power is the differential thermal expansion of the fuel and cladding. This differential expansion of the fuel and cladding provides the thermal-mechanical interaction forces to produce the stress and strains in the cladding which, in the presence of fast neutron radiation damage and/or chemically aggressive fission products, may promote failure of the Zircaloy cladding. There may also be additional factors such as:

a) the thermal-stress effect in promoting radial cracking of the fue 1 pellets, which are likely to cause stress and strain intensification in the Zircaloy cladding at the crack location; or

b) the thermal-transient effect [74] in promoting the relatively prompt release of fission products, some of which are chemically aggressive to the Zircaloy cladding.

3. The mechanicistic corollary to the fuel burnup (Bu) is postulated to be at least severalfold:

a) the accumulation of fission products within the fuel, some of which, when released, are chemically aggressive to the Zircaloy cladding;

b) the accumulation of fast neutron radiation damage of the Zircaloy cladding, which tends to enhance such stress-strain anomalies as the 
yield point, dislocation channeling as manifested by drop-in-load yielding* and strain localization, and the reduction in SEAF; and

c) cladding "creepdown" and fuel swelling, which may promote harder interfacial contact between the fuel pellet and the cladding, thereby intensifying the thermal-mechanical interaction force accompanying a specific transient increase in power.

One PCI fuel failure model [12], based on the information reported for Data Set 1, proposes a "dwell time" parameter. An examination of Data Set 1, however, suggests that the so-called "dwell time" is a characteristic of online refueling in PHWRs and not a unique characteristic of the PCI fuel failure phenomenon. An examination of Data Sets 1 and 5 and laboratory SCC experiments suggests that TTF may be a significant parameter in the PCI fuel failure phenomenon. Unes' [70] experiments further suggest an inverse proportionality between TTF and strain rate in the Zircaloy cladding. Furthermore, Unes' [70] results are consistent with the Monkman-Grant Rule [75], which states that, for failure by creep deformation, the product of the secondary creep rate and rupture time is a constant:

$$
\dot{\varepsilon} \cdot \mathrm{TTF}=\text { Constant }
$$

where: $\quad \dot{\varepsilon}=$ secondary creep-rate TTF = rupture time.

As previously noted, all of the fixed load SCC laboratory tests on Zircaloy $[13-15,18]$ were at load and temperature conditions that were conducive to

\footnotetext{
* Drop-in-load yielding, as used here, is defined as that characteristic of certain metals and alloys to continue to deform plastically under externallyapplied loads that are smaller than that necessary to cause the initial vielding.
} 
deformation by thermally activated creep. Recognizing that creep and stressrupture data are normally derived from fixed load and temperature conditions, SEAF is implicit in the Monkman-Grant Rule and may therefore be restated as follows:

$$
\sigma \cdot \dot{\varepsilon} \cdot \mathrm{TTF}=\mathrm{SEAF}]_{\mathrm{T}}=\text { constant }
$$

where: $\quad \sigma=$ applied stress

$$
\begin{aligned}
\dot{\varepsilon} & =\text { strain-rate } \\
T & =\text { temperature } \\
\Pi F & =\text { rupture time. }
\end{aligned}
$$

For materials that are interstitial-dislocation interaction sensitive and/or susceptible to SCC embrittlement, the Monkman-Grant Rule requires further modification. As shown in Figure 2.8, SEAF is not constant over wide ranges of strain rate, but rather appears to vary with strain rate, temperature, and environment in a systematic and predictable manner. In short, SEAF appears to be a useful constitutive material property to account for not only rate effects but also environmental effects in interstitial-dislocation interaction sensitive materials. If the data shown in Figure 2.8 are indeed representative of the effect of strain rate and environment on SEAF, then one may postulate a more generalized rule as follows:

$$
\left.\sigma \cdot \dot{\varepsilon} \cdot T T F=S E A F\rfloor_{T,} \dot{\varepsilon}=\text { constant }{ }^{-E}\right\rfloor_{\text {Envir }}
$$

where: $\quad \sigma=$ applied stress

$$
\dot{\varepsilon}=\text { strain rate }
$$$$
T=\text { temperature }
$$ 


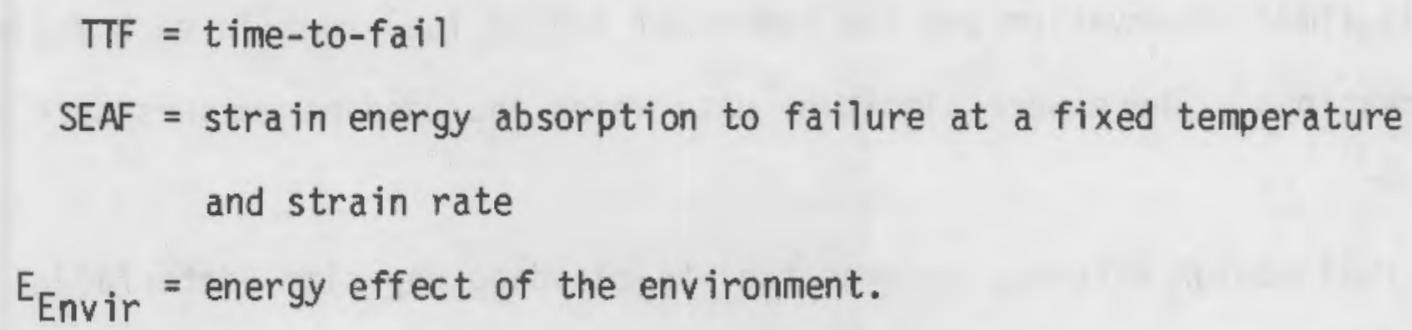

As noted previously, the fast neutron irradiation environment reduced SEAF by an essentially constant amount over the entire range of strain rates (see Figure 2.8). There is no specific data for Zircaloy to quantify the effect of an SCC environment. However, the observations by Parkins [60] and others [60-64] for other materials strongly suggest that the SCC environmental effect is likely to be generally analogous to that for irradiation (see Figures 2.9, 2.10, and 2.12).

If the mechanistic corollary to $\Delta \mathrm{P}$ in fuel rod assembly power is the differential thermal expansion of the fuel and cladding, then by the same logic $\dot{p}$ is the operating corollary of the rate of differential thermal expansion of the fuel and cladding. And if the increase in power is sufficient to strain the cladding, then $\dot{P}$ is the operating corollary of strain rate.

Based on the above considerations, empirical modeling of the available $P C I$ fuel failure data should include $P_{i}$ and/or $P_{f}, \Delta P, B u$, and $P$. These parameters were all considered here in modeling the PCI fuel failure phenomenon.

\subsection{DEVELOPMENT OF A FAILURE FUNCTION}

The PCI fuel failure data available for this study were identified almost entirely by the operating variables $P, \Delta P$, and Bu. Data Set 1 included a 
"dwe 11 time" observation and the number of failed fuel rods in each failed observations. There were almost no data which included parameters such as:

- $\dot{p} \star$

- fuel design effects, such as fuel-to-cladding gap size, interfacial lubricants or SCC inhibitors, prepressurization, etc.

- operating history for either failed or nonfailed fuel rods/assemblies

- neutronic aspects, such as local fuel rod power suppression, peak rod power positions, etc.

Approaches by which the available (P, $\triangle P$, and $B u$ ) PCI fuel failure data may be evaluated and a failure function derived are:

1. a critical value threshold approach requiring assurance from some independent or alternate source that the PCI fuel failure phenomenon is "threshold" controlled, and assurance that the available data include critical value data points, or

2. a regression or least squares surface fitting approach, which provides the best results when the data samples are of sufficient size and distribution and requires that the data are randomly distributed about the statistical mean surface/contour.

A threshold for PCI fuel failures may be estimated graphically by the development of its surface directly from the three-dimensional data coordinates, $P, \Delta P$, and $B u$. However, some apriori knowledge of the threshold surface/contour from an independent or alternate source was necessary to assure that the developed threshold surface is based on critical value data. In the

\footnotetext{
*Data Set 1 includes this information, but the range of power ramping rates is less than an order of magnitude.
} 
absence of definitive apriori knowledge of the PCI failure threshold, it became necessary to evaluate the PCI failure data by analytical and statistical regression methods.

Taking into account the limitations of the data, the selection of the PCI fuel failure analys is approach was based on the following requirements, assumptions, and/or critiera:

1. The assumption is made that each data point and each data set was as valid as any other, unless and/or until shown otherwise (in short, one model for all data).

2. Because PCI fuel failure data are spatially defined by the coordinates $P$, $\triangle P$, and $B u$, there must be a unique relationship between these parameters.

3. The method must be mathematically and statistically consistent for assigning a unique and single value failure probability.

4. The relationship between parameters should be substantiated by independent approaches and/or alternate fuel behavior parameters.

The approach was to determine, by regression analysis, the mean surface/contour for the PCI failure data in Data Sets 1 through 4 only. Data Set 5 was excluded since those data are far more experimental than statistical in character. If the four PCI failure data sets produce an acceptable mean surface/contour, then the combined failed and nonfailed data may be used to derive a failure function. The failure probabilities can then be estimated by means of this analytical function.

The data were segregated into relatively small and discrete burnup intervals to seek some pattern between $\Delta P$ and either $P_{i}$ or $P_{f}$. Figures 3.1 through 3.3 show the composite failed and nonfailed data segregated into 
$(\mathrm{kW} / \mathrm{m})$

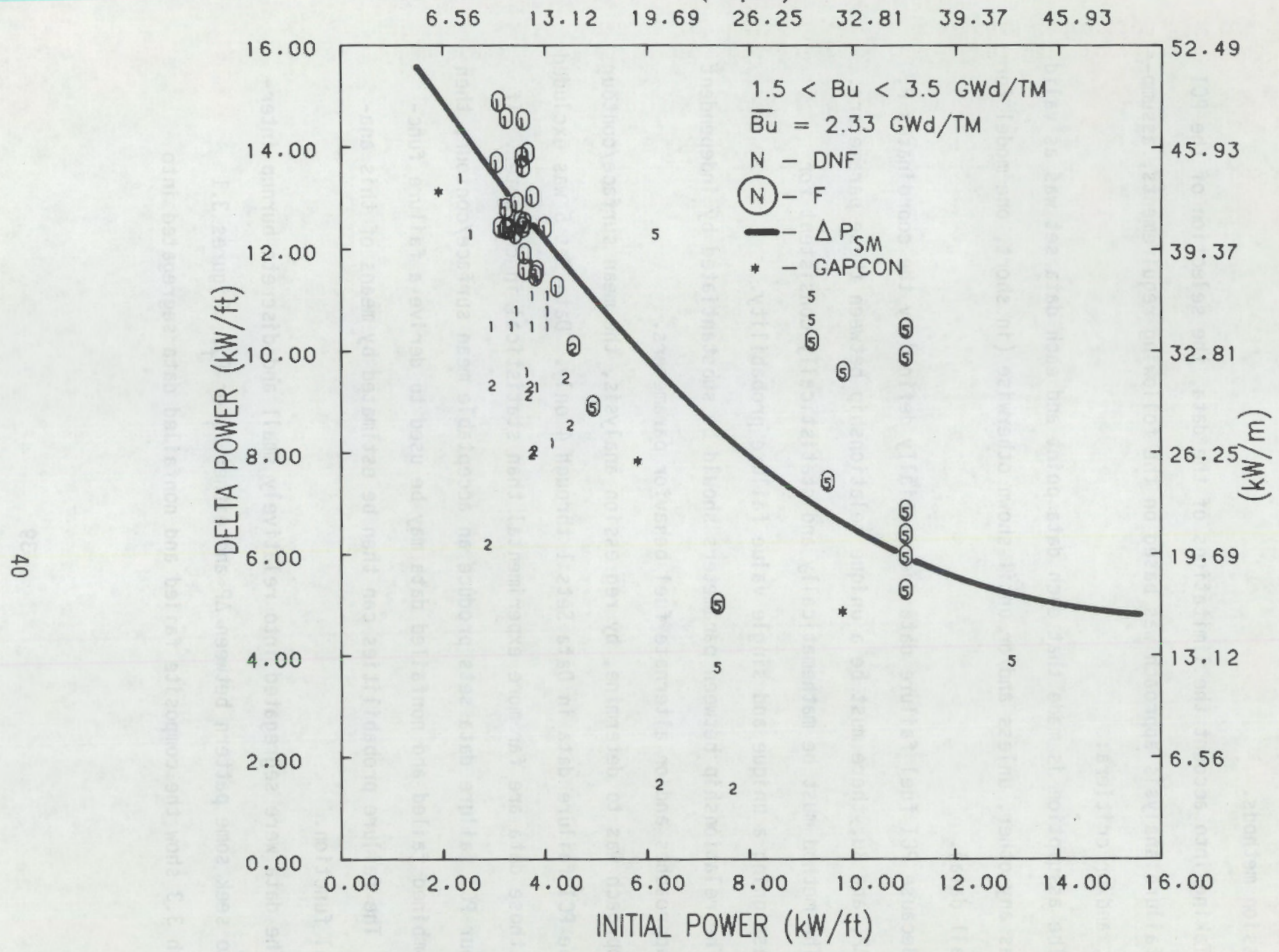

FIGURE 3.1. Shown are all Failed (F) and Did Not Fail (DNF) Fuel Data for This Burnup Interval. Also Shown is a Least Squares, Nonlinear

Regression Fit to the Failed Fuel Data and Three GAPCON-THERMAL-3 Transient Simulations. 


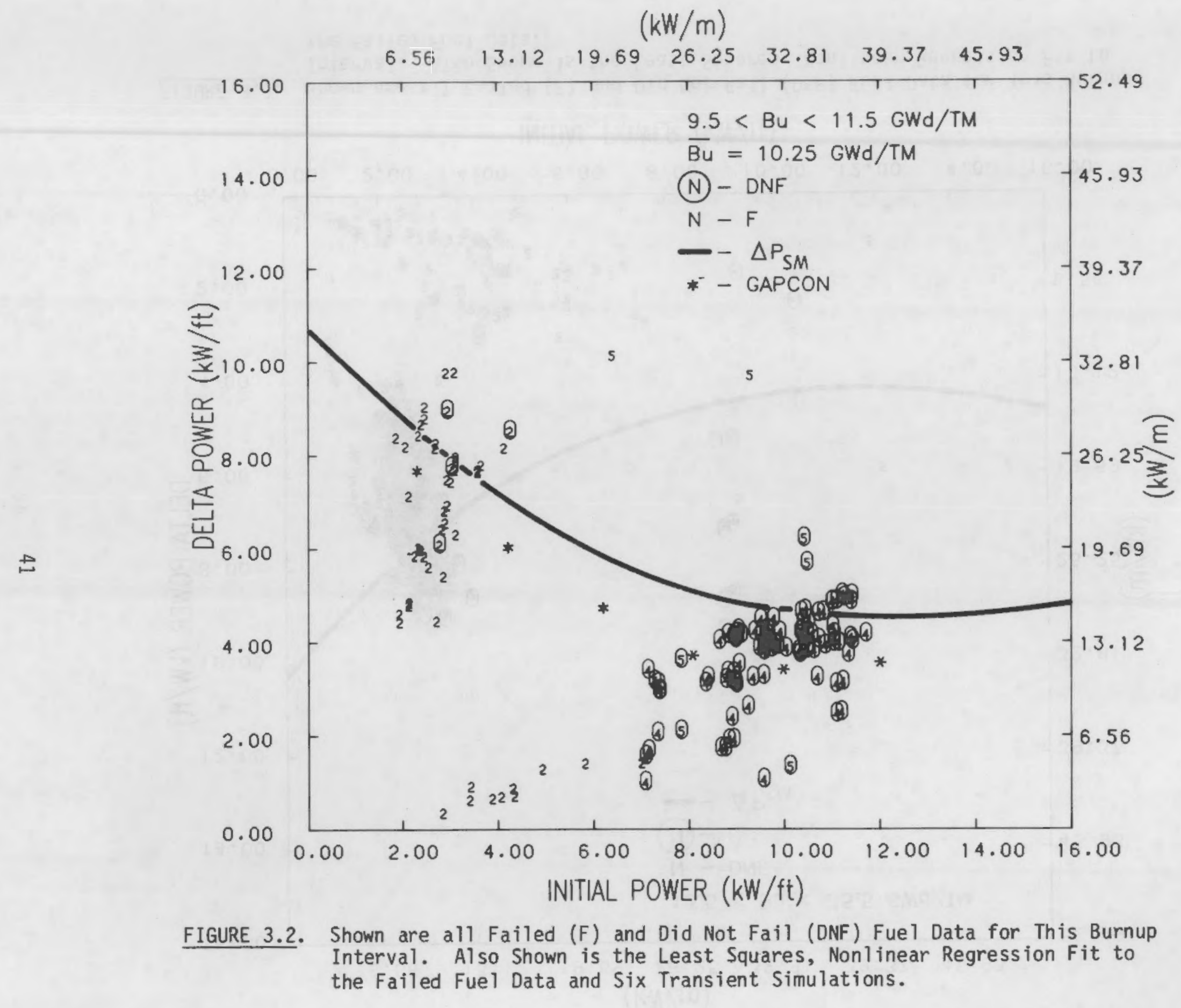




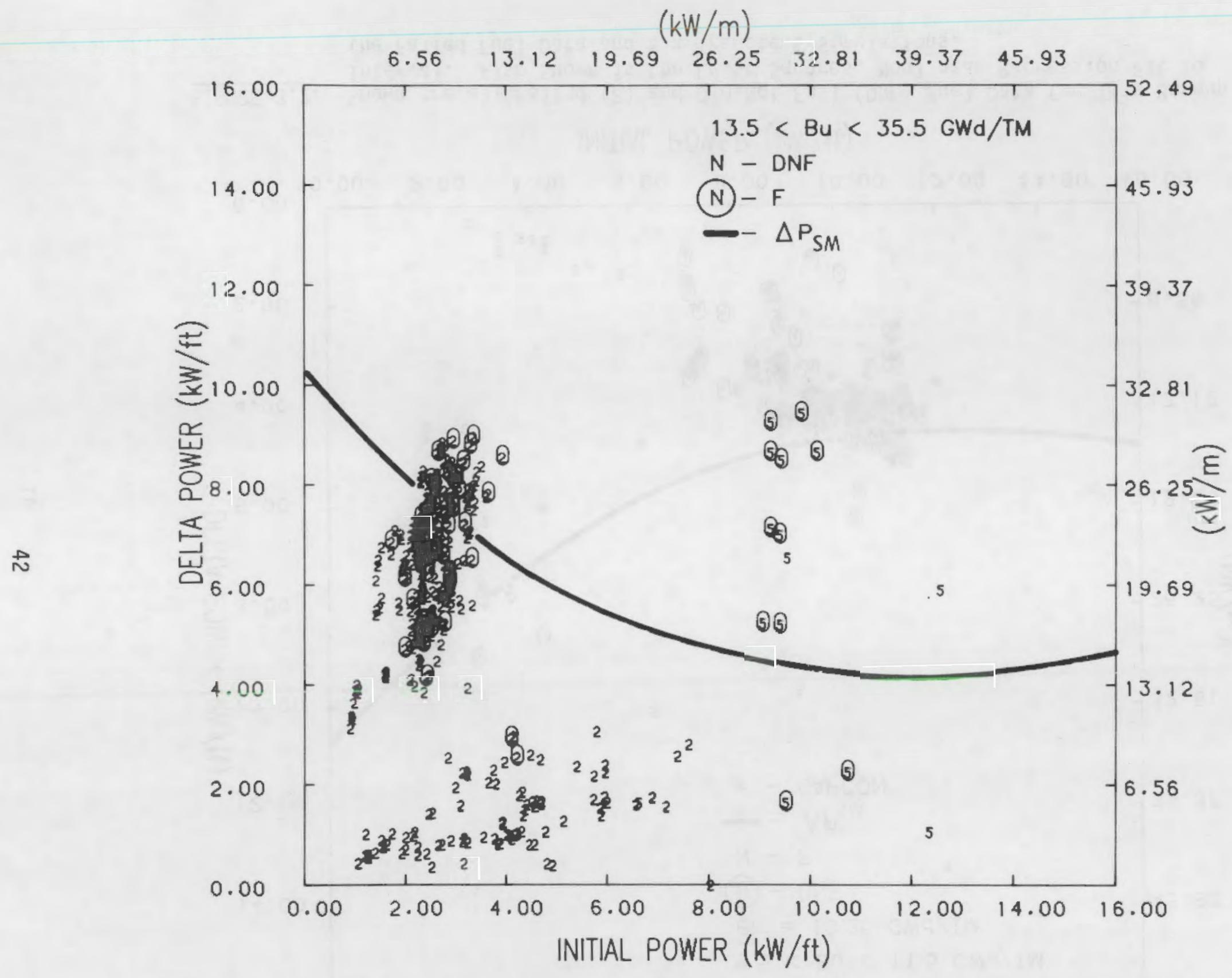

FIGURE 3.3. Shown are all Failed (F) and Did Not Fail (DNF) Fuel Data for This Burnup Interval. Also Shown is the Least Squares, Nonlinear Regression Fit to the Failed Fuel Data. 
discrete burnup intervals and the data set identification number (DNF - did not fail, F - failed) for each data set. Inasmuch as the burnup effect appears to approach an asymptote within the range of about 5 to $10 \mathrm{GWd} / \mathrm{MTM}$, all of the data within the range of $13.5<\mathrm{Bu}<35.5 \mathrm{GWd} / \mathrm{MTM}$ are shown in Figure 3.3. Least squares, linear and nonlinear regression methods, were applied to all of the failed data. The best fit to all of the failure data (taken from Data Sets 1 through 4) was obtained using least square, nonlinear regression methods and resulted in the following function:

$$
\Delta P_{S M}=\frac{A}{2} \cdot \cosh \left(\frac{P_{i}-P_{a}}{A}\right)
$$

and:

$$
P_{a}=B\left[1+e^{-C \cdot B u}\right]
$$

where: $\Delta P_{S M}=$ statistical mean transient increase in power for fuel failure

$$
\begin{aligned}
P_{i} & =\text { inital pre-transient power } \\
B u & =\text { fuel burnup } \\
A, B, C & =\text { constant coefficients. }
\end{aligned}
$$

As shown in Figures 3.1 through 3.3, the $\Delta P_{S M}$ function is superimposed on the composite data at the averaged burnup for the PCI fuel failures within each burnup interval. Figure 3.4 is a computer-generated plot of $\Delta \mathrm{P}$ versus $P_{i}$ from the nonlinear regression analysis of all the PCI fuel failure data in Data Sets 1 through 4. On this plot, the zeros (0) and a few of the dollar (\$) signs denote PCI failures, where these dollar signs represent two or more 
$\triangle P$ VS. $P_{\mathrm{i}} \quad U=$ UBSERVEO $\quad=$ FUNCTIUH

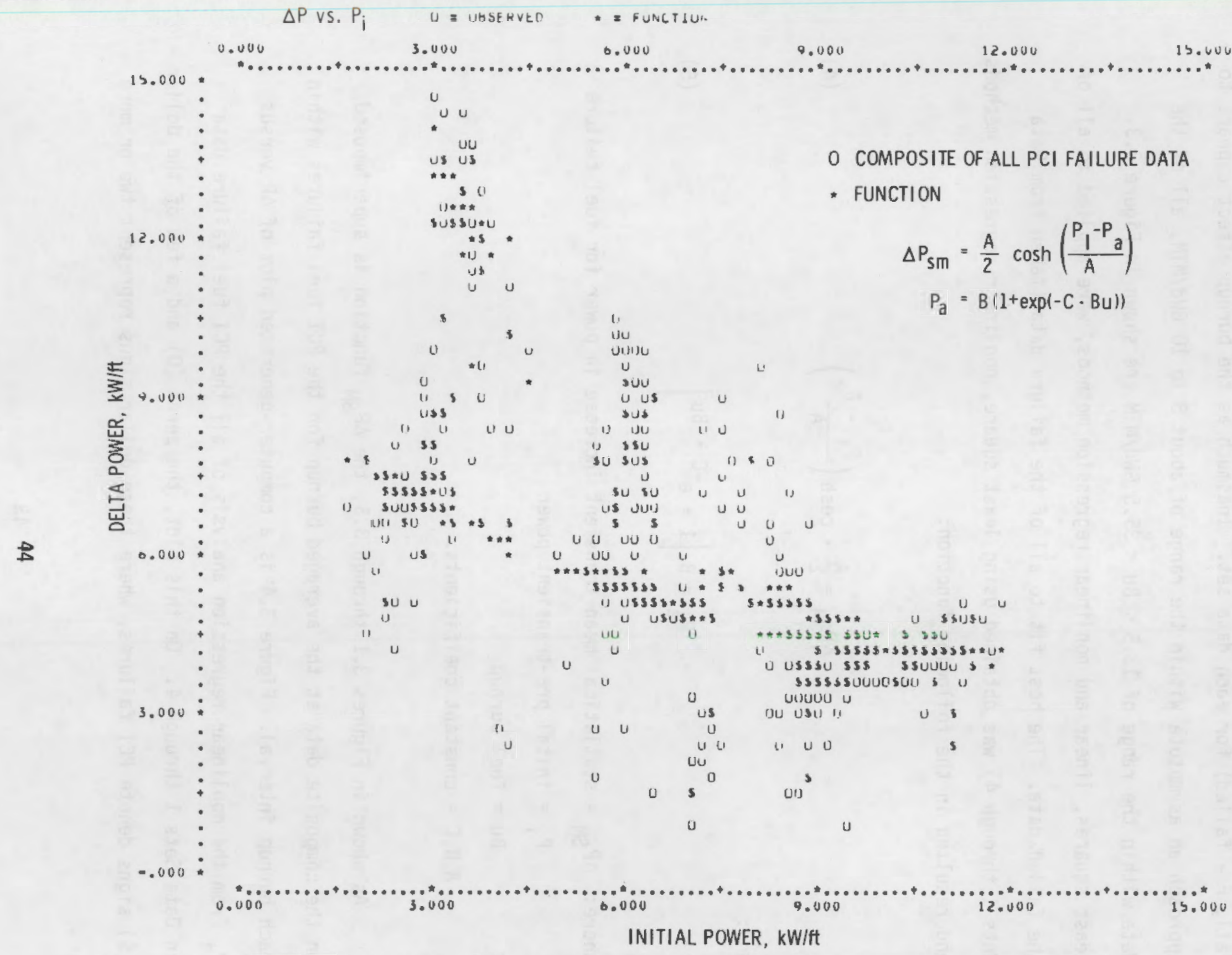

$$
\begin{aligned}
\Delta P_{\text {sm }} & =\frac{A}{2} \cosh \left(\frac{P_{1}-P_{a}}{A}\right) \\
P_{a} & =B(1+\exp (-C \cdot B u))
\end{aligned}
$$


coincident failure data points. The asterisks $\left(^{*}\right)$ denote the $\Delta P_{S M}$ versus $P_{i}$ failure function. The burnup effect appeared to approach an asymptote within about the $5 \mathrm{GWd} / \mathrm{MTM}$ to $10 \mathrm{GWd} / \mathrm{MTM}$ burnup range. Figure 3.5 shows the general distribution of the PCI failure observations about the statistical mean $\triangle P$ for Data Sets 1 through 4 . It is significant to note that the distribution about the mean is random.

\subsection{CORROBORATION FOR THE COSH FUNCTION}

As shown in Table 2.1, there is considerable diversity in the three fuel designs from which the PCI fuel failure data were derived. There also appears to be significant diversity in the transients in which the failures occurred (see Section 2). As previously noted, each data set occupies a rather limited volume of the three-dimensional space defined by the operating parameters $P$ (either $P_{i}$ or $P_{f}$ ), $\Delta P$, and $B u$. Under these circumstances, it seems unlikely that any individual data set would be wholly representative of the PCI fuel failure phenomenon. Regression analyses of the data sets individually do indeed show some disparity in the statistical mean surface/contour for the failure data in each of Data Sets 1 through 4 . Although the disparity in the statistical mean surface/contour was not generally great from data set to data set, it was considered necessary to attempt some independent corroboration of the $\mathrm{COSH}$ function as derived from the combined failure data. To obtain some independent corroboration of the COSH function, a number of transient power increase simulations were analyzed with the GAPCON-THERMAL-3 fuel performance

computer code [76]. In these transient simulations, a constant increment of circumferential strain $\left(\Delta \varepsilon_{\theta \theta}\right)$, which occurs in the transient only, is a measure 
$U=$ HESIDUALS

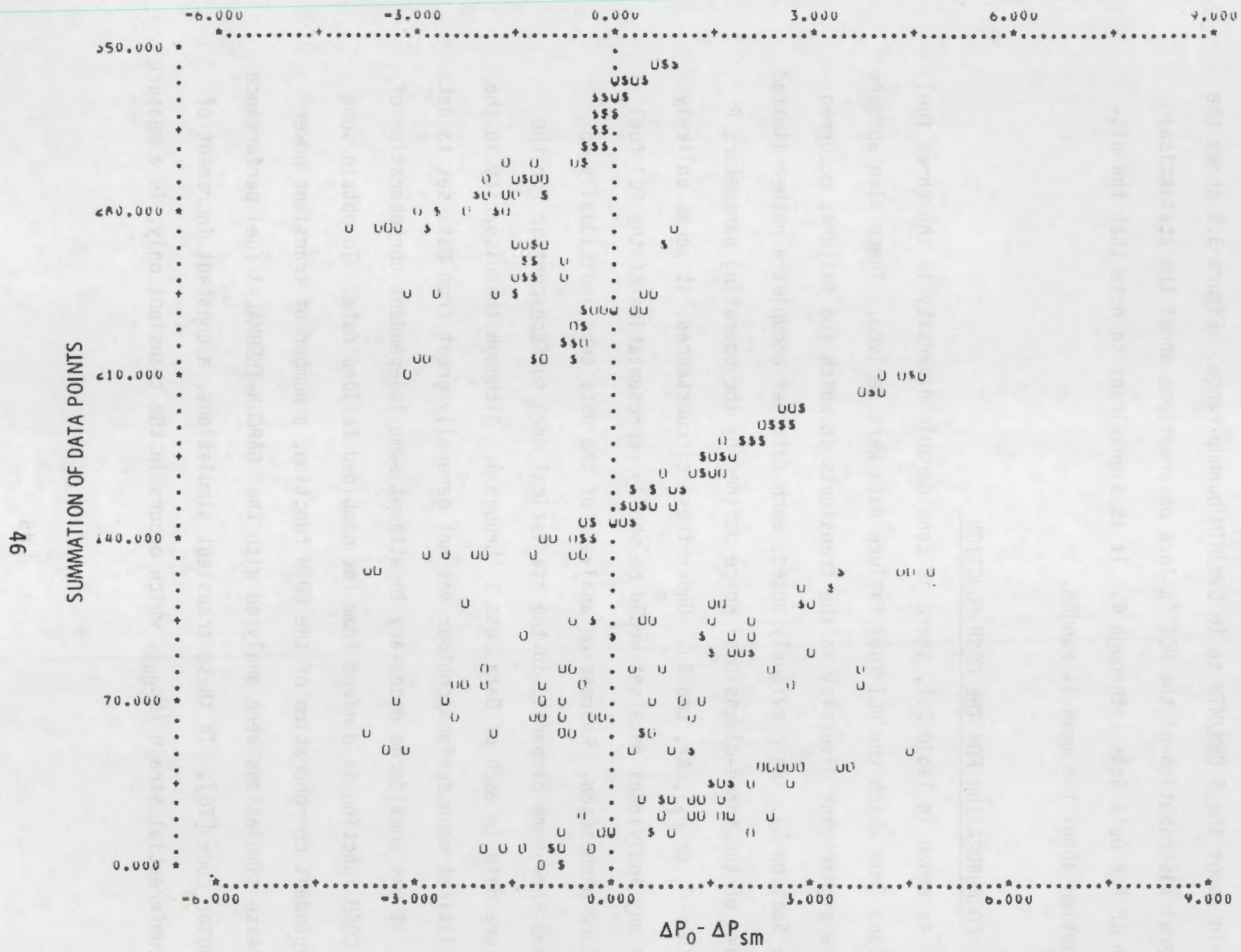

350.000

cev.0uo

210.000

140.000

70.000

FIGURE 3.5. A Computer-Generated Plot of the Difference Between the Observed and the Calculated Statistical Mean Delta Power for all PCI Failure Data. 
of that differential thermal expansion. The results of these transient simulations are shown in Figures 3.1 and 3.2. The similarity between the COSH function for the composite PCI failure data and the transient simulations appears to provide assurance that the statistical mean failure surface/contour determined from the fuel failure data can be used as a basis for a failure probability function.

\subsection{OTHER PCI FUEL FAILURE PARAMETERS}

Several additional parameters have been identified as pertinent to defining the operating conditions under which PCI fuel failure may occur.

Those operating parameters are TTF, $\dot{P}$, and the environmental effects of fast neutron flux irradiation and SCC on the SEAF characteristics of the Zircaloy cladding.

Within the scope of this study, there did not appear to be any first-order effect attributable to the differences in fuel rod designs represented in Data Sets 1 through 5. The logic in developing the COSH failure function, however, suggests that fuel rod design features that alter the magnitude of the thermomechanical interaction must be considered in applying the COSH failure function. Pre-pressurization of fuel rods with a high thermal conductivity fill gas is one design feature that alters the magnitude of the thermo-mechanical interaction. Likewise, any flux power-thermal mismatch that may occur in a power transient will also alter the magnitude of the thermo-mechanical interaction and must therefore be taken into account in applying the COSH failure function. Considering that the differential thermal expansions of the fuel and cladding is the mechanistic corollary of $\triangle P$ and the major stress/straining 
function in the PCI fuel failure phenomenon, then the thermo-mechanical interaction effects can be accounted for by a correction to the $\Delta P$ parameter.

As shown in Equation 3, SEAF appears to be a constitutive material property that can account for combined effects of strain rate, environmental embrittlement, and temperature in the failure of interstitical-dislocation interaction sensitive materials. Equation 3 further shows the strain rate and TIF interdependence.

Based on the previous discussions and the postulate that $\dot{P}$ is the operating corollary of strain-rate dependent deformation and failure mechanisms, it appears that the COSH failure and/or any other failure probability function should be modified to account for the strain-rate SCC embrittlement and plastic deformation characteristics of the Zircaloy cladding (see Figure 2.12). Recognizing that the composite PCI fuel failure data base probably encompasses a range of power ramping rates, it is suggested that at least some of the failures, which occurred in the least severe of the transients represented in the data base, may have been the consequence of power ramping conditions (rates) corresponding to strain rates in the Zircaloy cladding at which SEAF is a minimum (see figure 3.6). By the same logic, some of those failures that occurred in the more severe transients may have been the consequence of power-ramping/ strain-rate conditions for which SEAF is comparatively large. These considerations suggest that the likelihood of incurring PCI fuel failures in low severity transients could be as great or even greater than in the more severe transients.

It must, therefore, be recognized that, as shown in Figures 3.1 through 3.3, all failures which lie below the $\Delta_{S M}$ surface/contour do not necessarily 

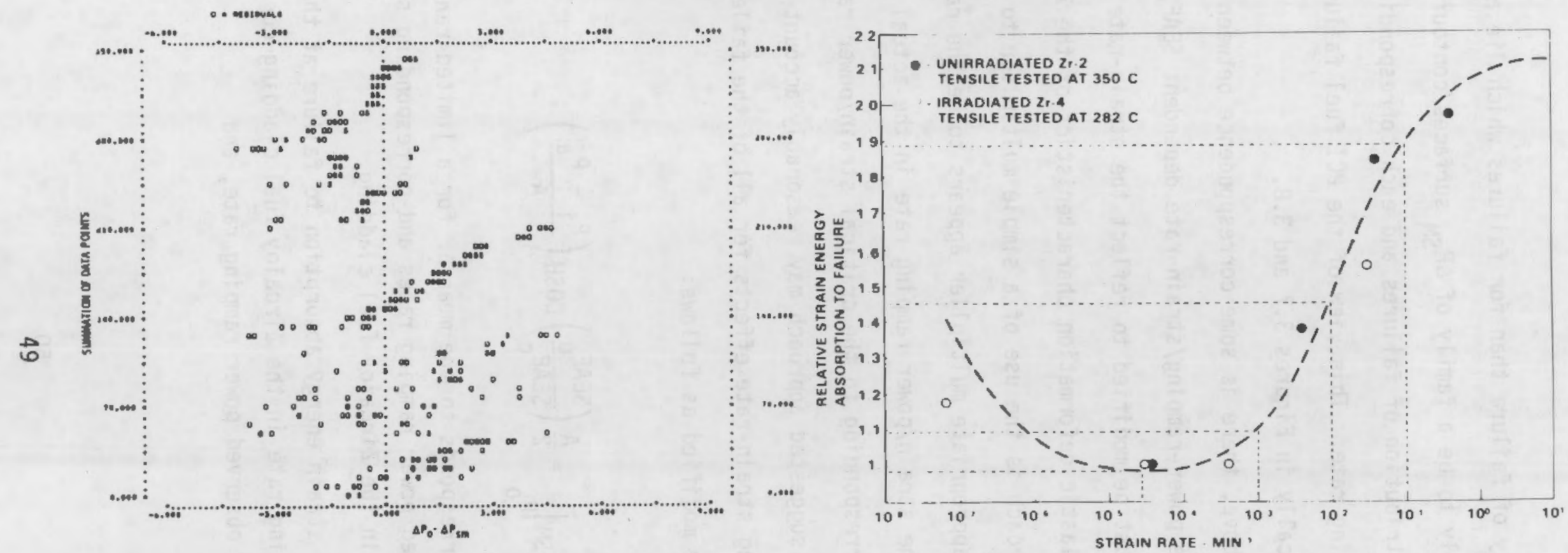

FIGURE 3.6. The Juxtaposition of Figures 2.8 and 3.5 to Suggest a Correspondence Between the Severity of the Transients in Which PCI Failures Were Observed and the Strain Rate Versus Strain Energy Absorption to Failure 
have a lower probability of failure than for failures which lie above $\Delta \mathrm{P}_{S M}$. In short, there is likely to be a family of $\Delta P_{S M}$ surfaces/contours, each with its own statistical distribution of failures and each corresponding to a specific strain/power ramping rate. This view of the PCI fuel failure phenomenon is illustrated schematically in Figures 3.7 and 3.8 .

If, as suggested above, there is some correspondence between the severity of the transient and the power-ramping/strain-rate dependent SEAF, then the $\mathrm{COSH}$ failure function must be modified to reflect the strain-rate sensitive SCC embrittlement and plastic deformation characteristics of the Zircaloy cladding. One possible approach is the use of a simple multiplier to the COSH failure function. One appropriate multiplier appears to be the ratio of the SEAF corresponding to the strain/power ramping rate in the actual transient and the minimum SEAF corresponding to the critical strain/power ramping rate. Assuming that the above suggested approach may reasonably account for powerramping/Zircaloy-cladding strain-rate effects for all of the failed data, the COSH failure may then be modified as follows:

$$
\left.\Delta P_{S M}\right|_{P_{0}}=\frac{A}{2}\left(\frac{\operatorname{SEAF}_{0}}{\operatorname{SEAF}_{C}}\right) \operatorname{CoSH}\left(\frac{P_{i}-P_{a}}{A}\right)
$$

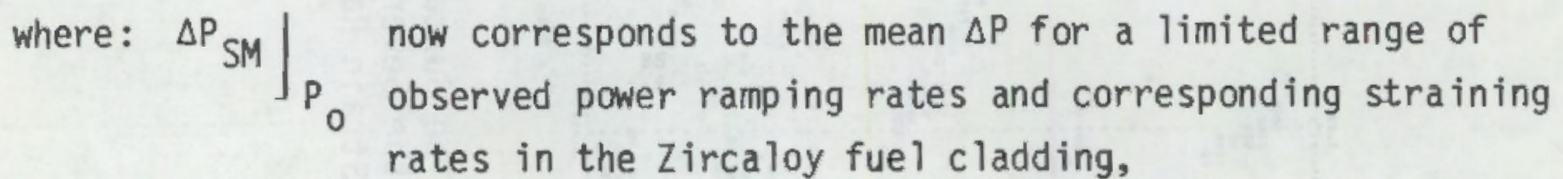

SEAF $_{0} \quad$ is the strain energy absorption to failure at the specific straining rate in the Zircaloy fuel cladding corresponding to the observed power ramping rate, and 


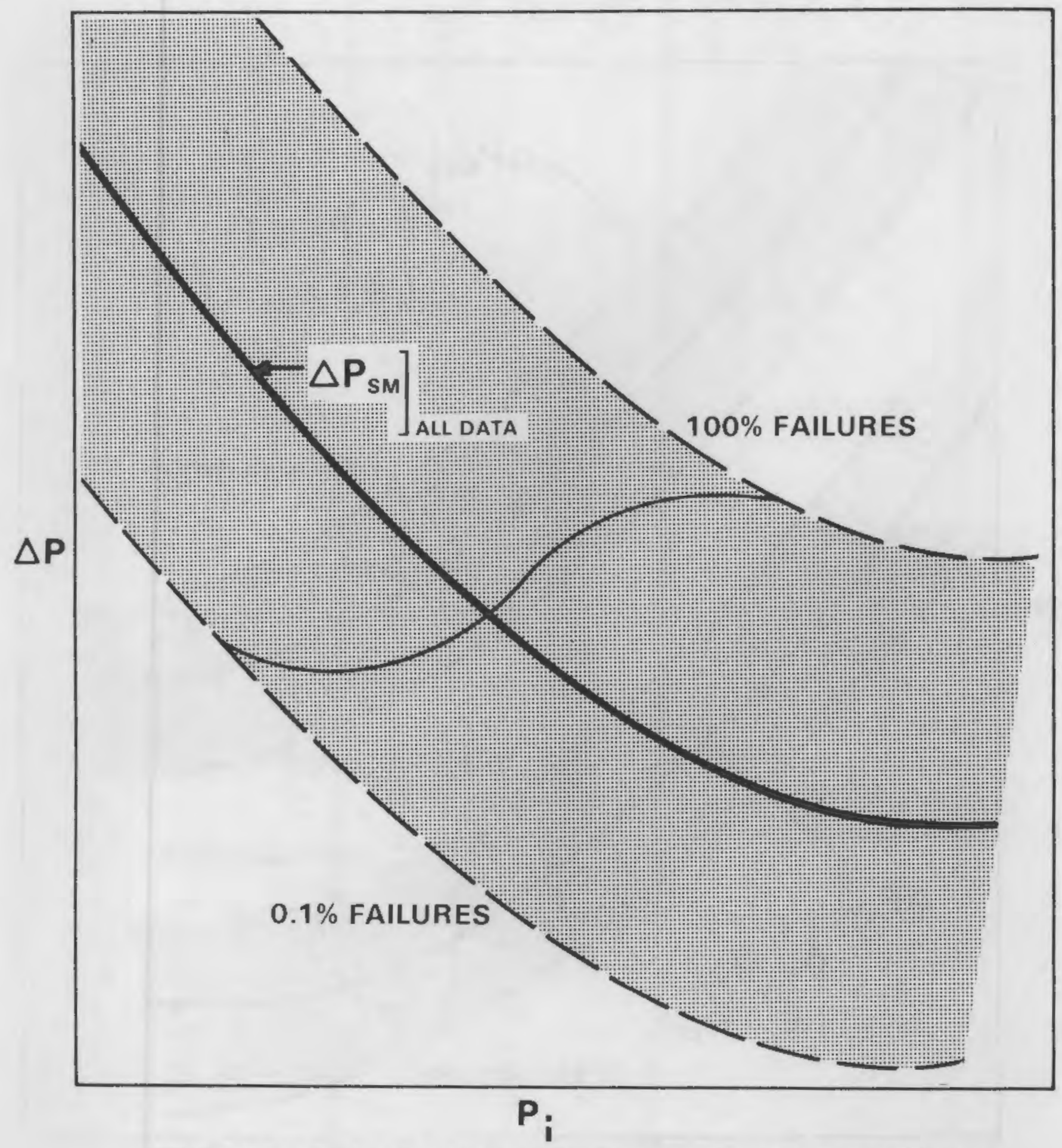

FIGURE 3.7. Postulated Failure Distribution About The Statistical Mean Assuming No Power Ramping Rate or Strain-Rate Effects on the Strain Energy Absorption to Failure Characteristics of the Zircaloy Cladding. 


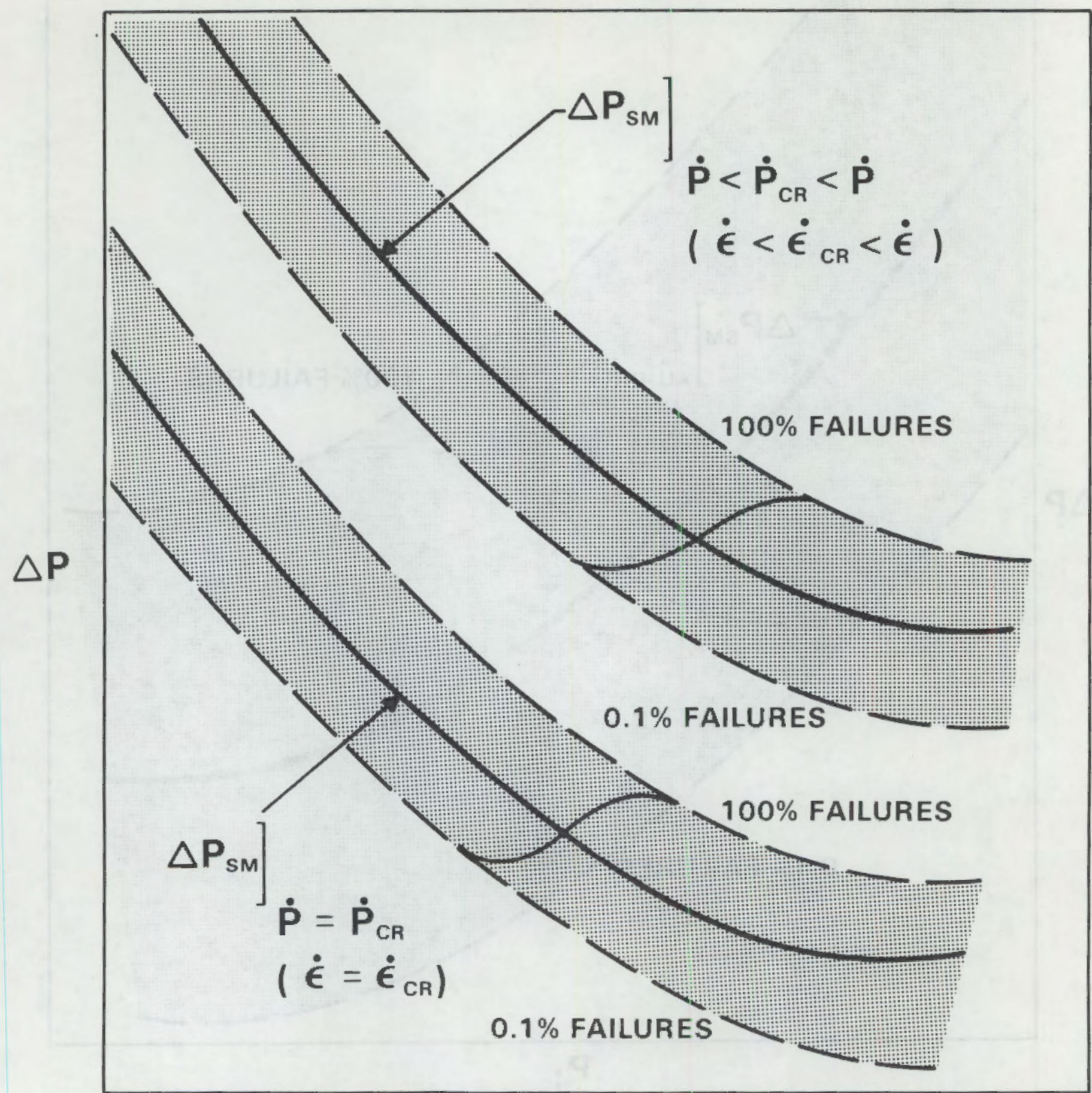

\section{P}

FIGURE 3.8. Postulated Failure Distribution About Each of a Family of Statistical Means, Each of Which Corresponds to a Spec if ic Power Ramping Rate. 


$$
\begin{aligned}
& \text { SEAF }_{c} \text { is the minimum in the strain energy absorption to failure } \\
& \text { at the critical straining rate in the Zircaloy fuel cladding } \\
& \text { corresponding to a critical power ramping rate. }
\end{aligned}
$$

The parameters $\mathrm{P}_{i}$ and $\mathrm{P}_{\mathrm{a}}$ and the coefficient $\mathrm{A}$ are all the same, as in Equation 4. The power ramping/strain rate/SEAF modification, as shown in Equation 6 , was applied to the COSH failure function in the belief that many, if not all, of the PCI failures in the composite data are likely to have occurred not only because of the severity of their transient increase in power, but also because their power ramping rate corresponded to a range of cladding straining rates for which SEAF is comparatively low or a minimum. Conversely, it appears likely that failure in the remainder of the composite data was avoided because their power ramping rates corresponded to cladding straining rates for which SEAF is comparatively large.

\subsection{FAILURE PROBABILITY}

Empirical methods have provided a basis for the development of at least some of the elements of a model of the PCI fuel failure phenomenon. The elements of this PCI failure model are:

1. the COSH function (Equations 4 and 5) to define the relationship between the three operating variables $P, \triangle P$, and $B u$ for the composite $P C I$ failure data, and

2. a multiplier to account, at least in part, for the strain (power ramping) rate and the SEAF behaviorial characteristics of the Zircaloy fuel rod cladding (Equation 6). 
Assuming that these elements of the PCI failure mode1 provide an acceptable representation of the PCI fuel failure phenomenon, they may then be combined with a model for estimating the probability of failure in transients.

Using standard statistical methods, a function based on the COSH failure function may be defined mathematically so it constitutes the surface/contour that best separates the failures from nonfailures. The PROFIT model is:

$$
S=\beta_{0}+\beta_{1} P_{0}-\beta_{2} \Delta P_{S M}\left(\frac{\text { SEAF }_{0}}{\operatorname{SEAF}_{c}}\right)
$$

where:

$$
\begin{aligned}
\Delta P_{S M} & =\frac{A}{2} \cos H\left(\frac{P_{i}-P_{a}}{A}\right) \\
P_{a} & =B\left[1+e^{-C \cdot B u}\right]
\end{aligned}
$$

The coeffients, $\beta_{0}, \beta_{1}$, and $\beta_{2}$, are selected to best separate the failures from non-failures. The parameters are as previously defined. Equation 7 may then be used in a logistic distribution function to provide an estimate of the probability of failure in transients as follows:

$$
\text { POF }=e^{S} /\left(e^{S}+1\right)
$$

Where: $\quad P_{i}=$ initial, pre-transient power $-\mathrm{kW} / \mathrm{ft}$

$$
\begin{aligned}
B u & =\text { fuel burnup }-\mathrm{GWd} / \mathrm{MTM} \\
\Delta \mathrm{P}_{0} & =\text { observed increase in power }-\mathrm{kW} / \mathrm{ft} \\
\Delta \mathrm{P}_{S M} & =\text { statistical mean increase in power }-\mathrm{kW} / \mathrm{ft}
\end{aligned}
$$




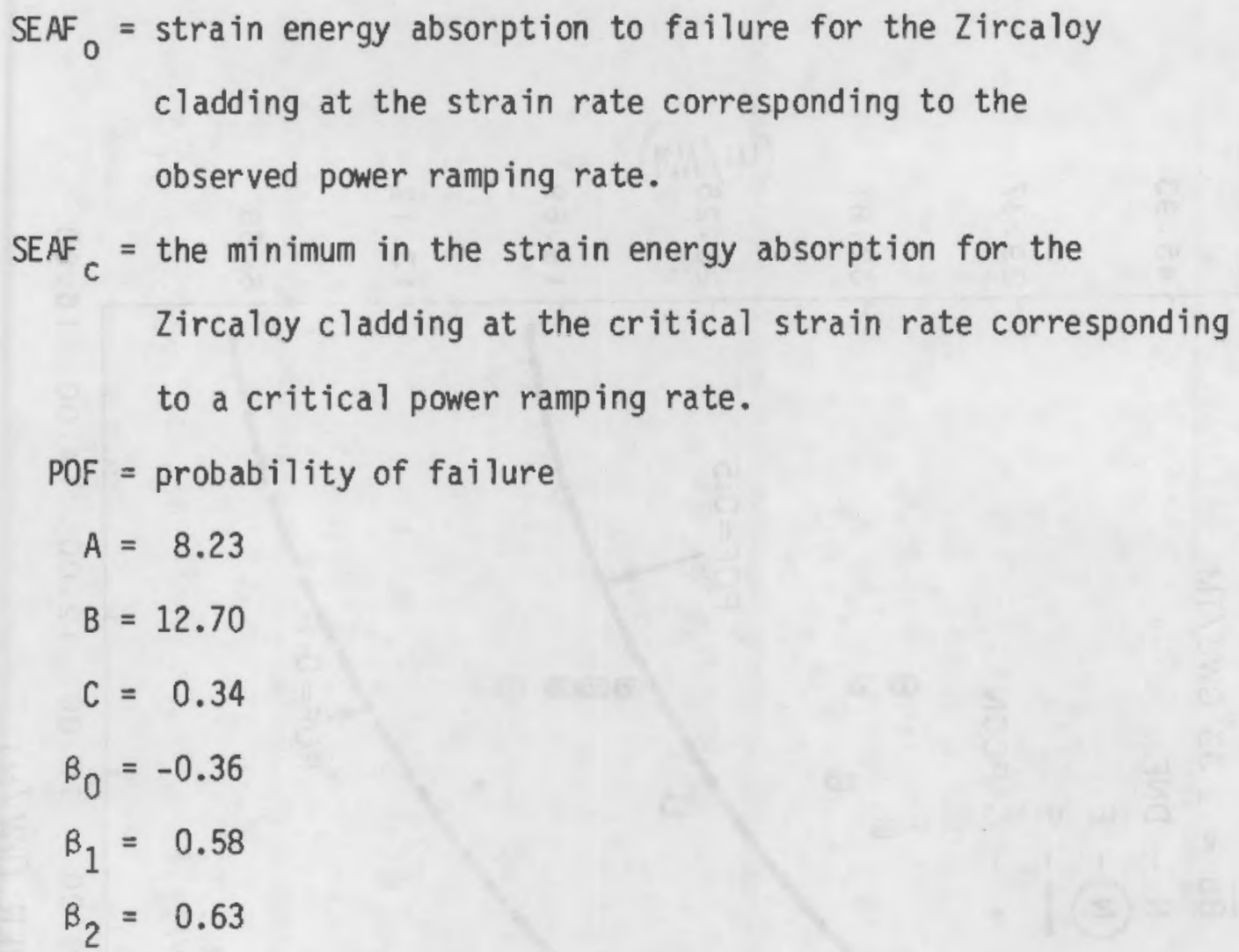

Figures 3.9 and 3.10 show the estimated probability of failure assuming a SEAF ratio of unity. Table 3.1 shows the postulated effect of strain/power ramping rate on the estimated probability of failure for several the SEAF ratios. As shown in Table 3.1, the postulated effect of the strain/power ramping rate on the probability of failure is substantial, particularly for the less severe transients.

Inasmuch as the composite data provided very little $\dot{\mathrm{P}}$ information, add $i$ tional data are needed to quantify the strain/power ramping rate and the SEAF relationship before more accurate PCI failure probabilities can be estimated from PROFIT. 


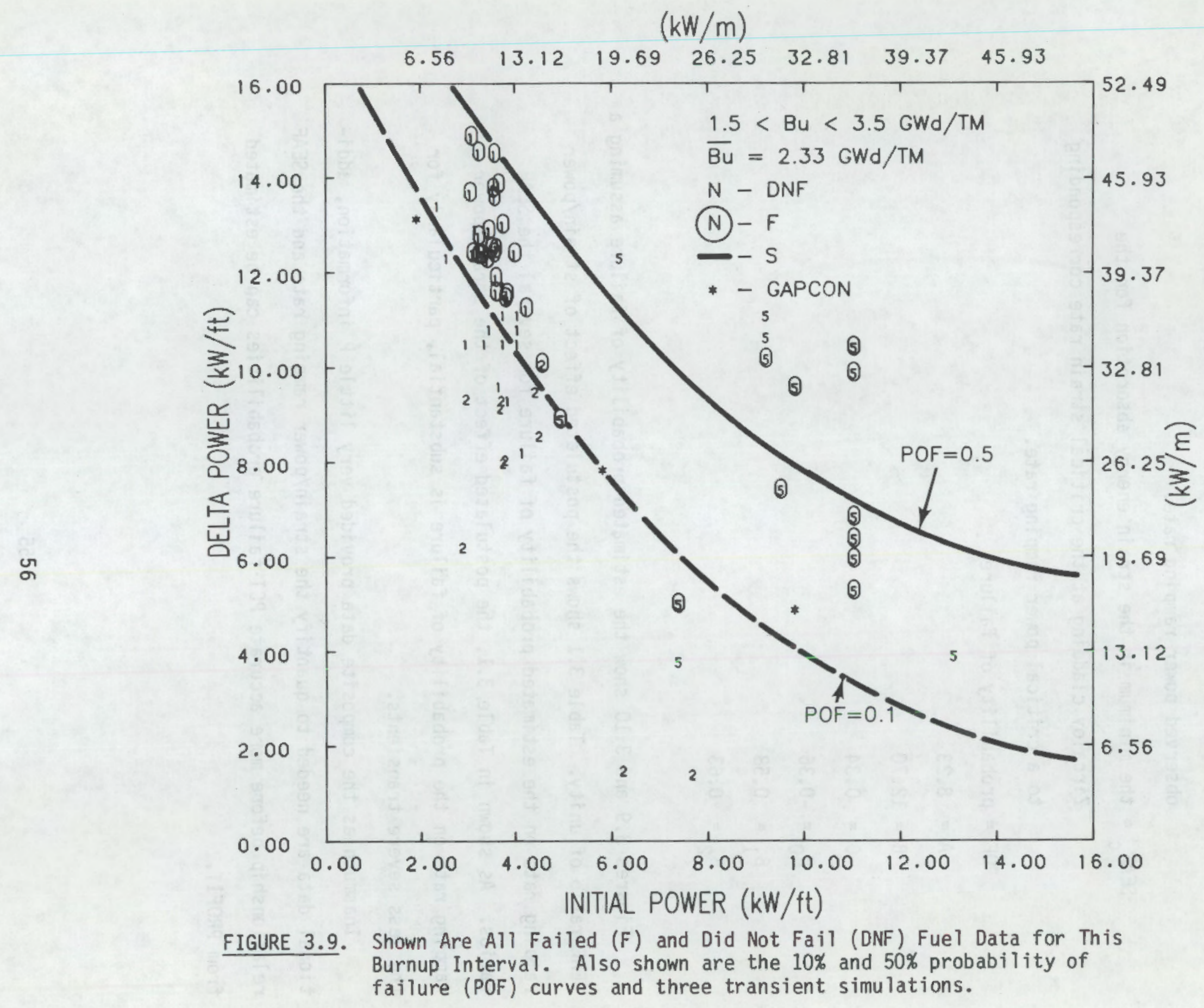




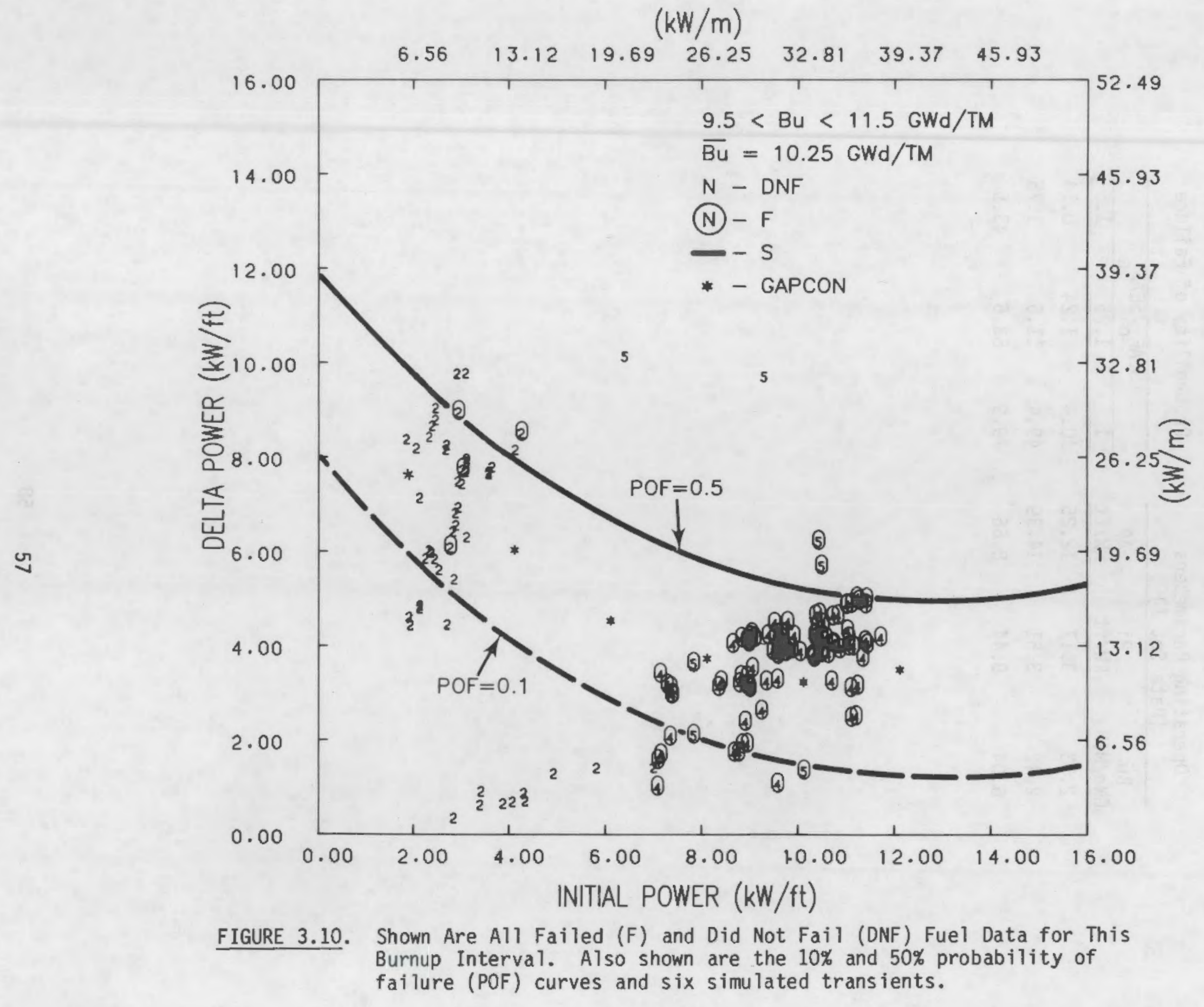


TABLE 3.1. Postulated Effect of Stra in/Power Ramping Rate on the Estimated Probability of Failure

\begin{tabular}{|c|c|c|c|c|c|}
\hline \multicolumn{3}{|c|}{$\begin{array}{c}\text { Operating Parameters } \\
\text { (Data Set 1) }\end{array}$} & \multicolumn{3}{|c|}{ Probability of Failure } \\
\hline $\mathrm{Bu}$ & $\mathrm{Pi}$ & $\Delta \mathrm{P}$ & & ${ }^{A F}{ }_{0} / S E$ & \\
\hline GWd/MTM & $\mathrm{kW} / \mathrm{ft}$ & $\mathrm{kW} / \mathrm{ft}$ & 1 & 1.25 & 1.5 \\
\hline 2.13 & 3.17 & 12.25 & 10.4 & 1.24 & 0.14 \\
\hline 2.42 & 3.51 & 14.39 & 49.4 & 11.6 & 1.75 \\
\hline 6.04 & 8.44 & 8.66 & 79.9 & 63.6 & 43.5 \\
\hline
\end{tabular}




\subsection{SUMMARY}

PROFIT is the result of the application of standard statistical regression methods to all available PCI fuel failure data and an analysis of the environmental and strain rate dependent stress-strain properties of the Zircaloy cladding. The PROFIT model introduces an environmental and strain rate dependent strain energy absorption to failure (SEAF) concept to account for strain rate effects in the interstitial-dislocation interaction sensitive Zircaloy fuel cladding. Assuming that the rate of increase in power $(\dot{P})$ is the operating corollary of strain rate $(\dot{\varepsilon})$, then the variables of first order importance in the PCI fuel failure phenomenon are postulated to be the pre-transient power $\left(P_{i}\right)$, the transient increase in power $(\triangle P)$, and burnup $(B u$,$) and the consti-$ tutive material property of the Zircaloy cladding SEAF. Because the effects of strain/power ramping rate on the SEAF characteristics of the Zircaloy cladding have not yet been systematicaliy investigated, no attempt was made to provide any estimates of SEAF/o to be used in the fuel failure model. 



\section{REFERENCES}

1. Bailey, W. J. 1974. "Fuel Failures in Commercial Nuclear Power Reactors." Pacific Northwest Laboratories, Richland, Washington 99352.

2. Judge, F. J., H. E. Williamson and D. T. Weiss. 1975. "A General Electric Fuel Performance Update." Trans. Am. Nuclear Society 20:249.

3. Bobe, P. 0. 1976. "Fuel Performance of Licensed Nuclear Power Plants Through 1974." NUREG-0032, Nuc lear Regulatory Commission, Washington, D.C.

4. Pitek, M. T. 1976. "Utility Experience in LWR Fuel Performance." NUSC0-115. Joint ANS/CNA Meeting, June 13-18, 1976, Toronto, Canada.

5. Elkins, R. B. 1977. Experience with 8WR Fuel Through December 1976. NEDO 21660, General Electric Company, San Jose, California.

6. Siege 1, B. L., and H. H. Hagen. 1977. "Fuel Failure Detection in Operating Reactors." NUREG 0401, Nuclear Regulatory Commission, Washington, D.C.

7. Wood, J. C. 1972-73. "Factors Affecting Stress Corrosion Cracking of Zircaloy in Iodine Vapor." J. Nuclear Materials 45:105-122.

8. Bain, A. S., J. C. Wood, C. E. Coleman. 1973. "Fuel Designs to Eliminate Defects on Power Increase." In Proceedings of the International Conference on Nuclear. Fuel Performance, October 15-19, 1973. British Nuclear Energy Society.

9. Wood, J. C., et al. 1975. "Environmentally Induced Fracture of Zircaloy by Iodine and Cesium: The Effects of Strain Rate, Localized Stresses and Temperature." J. Nuclear Materials 57:155-179. 
10. Wood, J. C., and D. C. Hardy. 1977. "Characteristics and Interpretation of Power Ramping Defects." ANS Meeting on Water Reactor Fuel Performance, May 9-11, 1977, St. Charles, Illino is.

11. Hardy, D. G., J. C. Wood and A. S. Bain. 1978. "CANDU Fuel Performance and Development." AECL-6213, Chalk River Nuc lear Laboratories, Chalk River, Ontario, K0J1J0.

12. Penn, W. J., R. K. Lo and J. C. Wood. 1977. "CANDU Fue l - Power Ramp Performance Criteria." Nuclear Technology 34:249-268.

13. Kreyns, P. H., G. L. Spahr and J. E. McCauley. 1975. An Analysis of Iodine Stress Corrosion Cracking of Zircaloy-4 Tubing. WAPD-TM-1203.

14. Tucker, R. P., P. H. Kreyns and J. J. Kearns. 1976. "The Effects of Internal Surface Flaws, Iodine Concentration and Temperature on the Stress Corrosion Cracking Behavior of Zircaloy-4 Tubing." Presentation at the ERDA/Industry Meeting on $\mathrm{UO}_{2}$ and $\mathrm{ThO}_{2}$ Fuel Rod Performance, ERDA Headquarters, Germantown, Maryland, January 29-30, 1976.

15. Garlick, A. 1973-74. "Fracture of Zircaloy Cladding Under Simulated Power Ramp Conditions." J. Nuclear Materials 49:209-224.

16. Grubb, W. T., and M. H. Morgan, III. 1977. "Cadmi um Embrittlement of Zircaloy-2." Proceedings in Conference on Water Reactor Fue 1 Performance, Chicago, I11inois. Amer. Nuclear Society, PP. 295-304.

17. Rosenbaum, H. S. 1978. "Demonstration of Fuel Resistant to Pellet-Cladding Interaction." Second Semiannual Report, January-June 1978. GEAP-32773-1.

18. Cubicciotti, D., and R. L. Jones. 1978. EPRI-NASA Cooperative Project on Stress Corrosion Cracking of Zircaloys. Final Report. EPRI NP-717, Stanford Research Institute. 
19. Strub, B. R. 1977. A Method for the Prediction of Boiling Water Reactor Fuel Failure. M. S. Thesis, Iowa State University.

20. Rolstad, E. 1976. "Model for Prediction of Fuel Failures." Trans. Am. Nuclear Soc. 24:163.

21. Mohr, C. L., et al. 1979. "PCI Fuel Failure Analysis: A Report on a Cooperative Program Undertaken by Pacific Northwest Laboratory and Chalk River Nuclear Laboratories." NUREG/CR-1163.

22. Djurle, S., and H. Taylor. 1969. Post-Irradiation Evaluation of the Third Swedish Fuel Assembly, IFA-21, Irradiated in the Halden Boiling Heavy Water Reactor. HPR-114.

23. Djurle, S., G. Lysell and H. Morgard. 1971. "Some Irradiation Studies of Fuel Cladd Interaction and Clad Cracking." A/CONF 49/P/315, May 1971, Sweden.

24. Aas, S., K. O. Olshausen, K. Videm. 1973. "Fuel Failures Caused by Overpower Ramps." In Proceedings of the International Conference on Nuclear Fuel Performance, October 15-19, 1973, British Nuclear Energy Society.

25. Rolstad, E., et a1. 1973. "Oimensional Changes of the Fuel and the Resulting Cladding Integrity Problems Under Irradiation." Transactions of CREST Specialist Meeting, October 1973, Saclay, France.

26. Bozzoni, T., G. Pugnetti and G. Valli. 1973. "Irradiation Experience in the Deve lopment of a Fuel Element for the Prototype CIREN Reactor." In Proceedings of the International Conference on Nuclear Fuel Performance, October 15-19, 1973, British Nuc lear Energy Society. 
27. Chagrot, M., D. Ringot and H. Vidal. 1973. "The Behavior of Zircaloy-UO $\mathrm{U}_{2}$ Fuel Elements Working at Low Temperature $\left(300^{\circ} \mathrm{C}\right) . "$ In Proceedings of the International Conference on Nuclear Fuel Performance, October 15-19, 1973, British Nuc lear Energy Society.

28. Knudsen, P., H. H. Hagen and J. St iff. 1973. "Overpower Testing of $\mathrm{UO}_{2}$-Zr Fuel Pins." Transaction of CREST Speccialist Meeting, October 1973, Saclay, France.

29. Lysell, G. 1973. "Overpower Experiments on IFA-5 Fuel Rods in R2 at Studsvik." Transaction Enlarged Halden Programme Group Meeting, December 1973, Halden, Norway.

30. Lysell, G., and G. Valli. 1973. "Overpower Ramp Tests on CIRENE Prototype Fuel Pins." In Proceedings of the International Conference on Nuclera Fuel Performance, October 15-19, 1973, British Nuc lear Energy Society.

31. Rolstad, E., and K. Svanholm. 1973. "Overpower-to-Failure Experiment on a High Burnup Fuel Rod." In Proceedings of the International Conference on Nuclear Fuel Performance, October 15-19, 1973, Brit ish Nuclear Energy Society.

32. Knudsen, P., and N. Kjaer-Pederson. 1975. "Performance Analys is of PWR Power Ramp Tests." ASME Transactions, Decemjer 1975, Houston, Texas.

33. Sipush, P. J. 1975. "Power Ramp Demonstrations in Westinghouse PWRs." WCAP-8531.

34. Furhman, N., et aT. 1976. "Evaluation of Fuel Performance in Maine Yankee Core I." EPRI NP-218, Project 586-1. 
35. Svanholm, K. 1977. "The Fourth Series of Overpower Tests in IFA-405." Paper presented at the Enlarged Halden Programme Group Meeting, March 8-12, 1976, Sanderstollen, Norway.

36. Borresen, S., D. L. Pomeroy, E. Rolstad and T. 0. Sauar. 1977. "Nuclear Fuel Performance Evaluation." EPRI NP-409.

37. Corda11, D., R. M. Corne 1, K. W. Jones and J. S. Waddington. 1977. "Fuel Failure in the Dodward Boiling Water Reactor." Nuclear Technology 34.

38. Svanholm, K. 1976. "Overpower Tests in IFA-405." Paper presented at the Enlarged Halden Programme Group Meeting, March 8-12, 1976, Sanderstollen, Norway.

39. Troiano, A. R. 1960. "The Role of Hydrogen and Other Interstitials in the Mechanical Behavior of Metals." 1959 Edward DeMille Campbel1 Memorial Lecture, Transactions of the American Society for Metals, Vol. 52 (1960), pp. 54-80.

40. Donoso, J. R., and R. E. Reed-Hill. 1976. "Slow Strain Rate Embrittlement of Niobium by 0xygen." Metallurgical Transactions, Series A, 7A:961-5

41. Donoso, J. R., A. T. Santhanam and R. E. Reed-Hill. 1978. "Slow Strain-Rate Embrittlement of Metals." Second International Conference on Mechanical Behavior of Materials 1976, American Society for Metals (Special Volume).

42. Reed-Hill, R. E. 1972. "The Tensile Properties of a-Zirconium." Reviews on High Temperature Materials 1(2):97-154. 
43. Ramachandran, V., et al. 1973. "Dislocation-Solute Interactions and Mechanical Behavior of Zirconium and Titanium." Indian Journal of Technology II : 485-492.

44. Ramachandran, V., and R. E. Reed-Hi11. 1970. "Dynamics Strain Aging and Ductility Minima in Zirconium." Metallurgical Transactions 1:2105-2109.

45. Veever, K., W. B. Rotsey and K. R. Snowden. 1969. "The Effect of Neutron Irradiation and Cold Work on the Strain-Aging Behavior of Zircaloy-2." Applications-Related Phenomena for Zirconium and Its Alloys, ASTM STP 548, American Society of Testing and Materials, pp. 194-209.

46. Pankaskie, P. J. "Irradiation Effects on the Mechanical Properties of Zirconium and Dilute Zirconium Alloys - A Review." BN-SA-618. (To be published in ASM Metals Handbook.)

47. Bement, A. L. 1967. "Symposium on Radiation Effects." American Institute of Mining, Metallurgical and Petroleum Engineers 37:671.

48. Shober, F. R., et al. 1963. "Investigation of the Yield Phenomenon in Zircaloy-2 at Elevated Temperatures." UC-25 Metals, Ceramics and Materials (TID-4500, 18th Ed.) Report No. BMI-1616.

49. Weinstein, D. 1966. "Yield Point Occurrence in Polycrystalline Alpha-Zirconium." Electrochemical Technology 4:7-8.

50. Fearenough, G. D., and A. Cowan. 1967. "The Effect of Hydrogen and Strain Rate on the "Ductile-Brittle' Behavior of Zircaloy." Materials 22:137-147.

51. Sabol, G. P., and S. G. McDonald. 1976. "Strain-Rate Dependent Mechanical Response of Zircaloy-4." J. Nuclear Materials. 
52. Thorpe, W. R., and I. O. Smith. 1979. "Tensile Properties of Zr-1 wt\% Nb Alloy." J. Nuclear Materials 78:49-57.

53. Hardy, 0. G. 1970. "The Effect of Neutron Irradiation on the Mechanical Properties of Zirconium Alloy Fuel Cladding in Uniaxial and Biaxial Test." Irradiation Effects on Structura] Alloys for Nuclear Reactor Applications. ASTM STP 484, American Society for Testing and Materials, pp. $215-158$.

54. Pankaskie, P. J. 1962. "Creep Properties of Zircaloy-2 for Design Application." HW-75267.

55. Fidleris, V. 1975. "Sumary of Experimental Results on In-Reactor Creep and Irradiation Growth of Zirconium Alloys." Atomic Energy Review 13:1.

56. Fidleris, V. 1978. "Primary Creep of Zircaloy-2 Under Irradiation." Fourth International Conference on Zirconium in the Nuclear Industry, June 27-29, 1978, Stratford-Upon-Avon.

57. Williams, D. N. 1963. "The Hydrogen Embrittlement of Titanium Alloys." J. of the Institute of Metals $91: 147-152$.

58. Lee, D. 1970. "The Strain Rate Dependent Plastic Flow Behavior of Zirconium and Its Alloys." Meta]lurgical Transactions 1:1607.

59. Azzarto, F. J., et al. 1969. "Unirradiated, In-Pile and Post-Irradiation Low Strain Rate Tensile Properties of Zircaloy-4." $\underline{\text { J. }}$ Nuclear Materials 30:208-218.

60. Parkins, R. N. 1977. "The Development of Strain Rate Testing and Its Implication." ASTM STP 665, pp. 5-24. ASTM Symposium on Evaluation Criteria for Determining the Susceptibility of Stainless Steels to Intergranular Corrosion, May 1-6, 1977, Toronto. 
61. Reinoeh I, J. E., and W. K. Boyd. 1971. "The Use of Slow Strain-Rate Experiments in Evaluating Resistance to Environmental Cracking." AGARD-CP-98. Paper presented at the Structures and Materials AGARD, 33rd Meeting, October 5-6, 1971, Brussels, Belgium.

62. Wearmouth, W. R., G. P. Dean and R. N. Parkins. 1973. "Role of Stress in the Stress Corrosion Cracking of a Mg-Al Alloy." NACE 29:6.

63. Scul1y, J. C., and T. A. Adepoju. 1977. "Stress Corrosion Crack Propagation in a Ti-O Alloy in Aqueous and Methanolic Solutions." Corrosion Science 17:789-812.

64. Bradford, S. A., and T. Lee. 1978. "Effect of Strain-Rate on Stress Corrosion Cracking of Brass." Corrosion, NACE.

65. Peehs, M., H. Stehle, E. Steinberg. 1978. "Out-of-Pile Testing of Iodine Stress Corrosion Cracking in Zry Tubing Under the Aspect of PCI-Phenomenon." ASTM STP 681, 1979, pp. 244-260.

66. Coffin, L. F. 1978. The Localized Ductility Method for Evaluating Zircaloy-2 Cladding. Report No. 78 CRD155, General Electric Company.

67. Tomalin, D. S. 1977. "Localized Ductility of Radiated Zircaloy-2 Cladding in Air and Iodine Environment." ASTM-STP-633.

68. Lee, D., and R. B. Adamson. 1977. "Modeling of Localized Deformation in Neutron Irradiated Zircaloy-7." ASTM-STP-633.

69. Zebroski, E. L., and J. T. A. Roberts. 1977. "EPRI Zircaloy Properties Program." Invited paper--Fifth Water Reactor Safety Research Information Meeting, November 7-11, 1977, UNSBS, MD. 
70. Une, K. 1979. "Effects of Strain-Rate, Stress Condition and Environment on Iodine Embrittlement of Zircaloy." Proceedings of the ANS Topical Meeting on Light Water Reactor Fuel Performance, Portiand, Oregon, April 29-May 3, 1979.

71. Buhl, H. 1979. "Validity of the Slow Straining Test Method in the Stress Corrosion Cracking Research Compared with Conventional Techn iques." ASTM-STP-665, pp. 333-346.

72. Kim, C. D., and B. E. Wilde. 1979. "A Review of the Constant Strain-Rate Stress Corrosion Cracking Test." ASTM-STP-665, pp. 97-112.

73. Andrew, J. F., J. T. Heron, and J. Stringer. 1979. "Some Compar isons of the Slow Strain-Rate Method with Constant Strain and The Constant Load Methods of Stress Corrosion Testing." ASTM STP 665, pp. 362-372.

74. Pankaskie, P. J. 1978. The Impact of Pellet-Cladding Interaction on Fuel Integrity - A Status Report. PNL-2667, Pacif ic Northwest Laboratory, Richland, Washington 99352.

75. Monkman, F. D., and N. J. Grant. 1956. "An Empirical Relationship Between Rupture Life and Minimum Creep Rate in Creep-Rupture Tests." ASTM 56:91-103.

76. Lanning, D. D., et al. 1978. GAPCONTHERMAL-3 Description. PNL-2434, Pacific Northwest Laboratory, Richland, WA 99352. 



\section{ACKNOWLEDGMENTS}

This work was performed for the Core Performance Branch, Division of Systems Safety, U.S. Nuclear Regulatory Commission. The author wishes to acknowledge the support and encouragement of R. 0 . Meyer and M. Tokar of the Reactor Fuels section of the Core Performance Branch. The author also acknow1edges the assistance of R. L. Goodman and N. J. Wildung, Pacific Northwest Laboratory, for the computer simulations and analys is of the data.

The author also wishes to acknowledge the data contributions from the Comonwealth Edison Company, Electric Power Research Institute, Exxon Nuclear Corporation, and the General Electric Company, without which this study would not have been possible. 

NUREG/CR-1462

PNL-3386

\section{DISTRIBUTION}

\section{OFFSITE}

\section{UNITED STATES}

A. A. Churm

DOE Patent Division

$9800 \mathrm{~S}$. Cass Avenue

Argonne, IL 60439

375 Nuclear Regulatory Commission

Division of Technical Information and Document Control

7920 Norfolk Avenue

Bethesda, MO 20014

2 DOE Technical Information Center

D. E. Bessette

Advisory Committee on Reactor Safeguards

U. S. Nuclear Regulatory Commission

1717 "H" Street, N.W.

Washington, DC 20555

R. N. Duncan

Combustion Engineering

1000 Prospect Hill Road

Windsor, CT 06095

F. E. Gelhaus

Electric Power Research Institute

3412 Hillview Avenue

P. 0. Box 10412

Palo Alto, CA 94304

Don A. Hoatson

Fue] Behavior Research Branch

Division of Reactor Safety

Office of Nuclear Regulatory

Research

U. S. Nuclear Regulatory Commission Washington, DC 20555
W. V. Johnston

Chief, Fuel Behavior Research

Branch

Division of Reactor Safety Research

Office of Nuclear Regulatory

Research

U. S. Nuclear Regulatory Commission Washington, DC 20555

W. M. Kiefer

Commonweal th Edison

72 W. Adams

Chicago, IL 60690

H. H. Klepher

General Electric Company

Nuclear Energy Division

175 Curtner Avenue

San Jose, CA 95126

Chief, Core Performance Branch

Division of Systems Integration

office of Nuclear Reactor

Regulation

U. S. Nuclear Regulatory Commission Washington, OC 20555

Jerome Lee

Tennessee Valley Authorjty

1410 Conmerce Union Bank B1dg.

Chattanooga, TN 37401

A. Lowe

Babcock and Wilcox Company

P. 0. Box 1260

Lynchburg, VA 24505 
George Marino

Fuel Behavior Research Branch

Division Reactor Safety Research

office of Nuclear Regulatory

Research

U.S. Nuclear Regulatory Commission Washington, DC 20555

\section{R. 0. Meyer \\ Core Performance Branch \\ Division of Systems Integration \\ Dffice of Nuclear Reactor \\ Regulation \\ U.S. Nuclear Regulatory Comitission \\ Washington, DC 20555}

P. A. Morris

Scandpower, Inc.

4853 Code11 Avenue

Bethesda, MD 20014

J. Owsley

Exxon Nuclear Company, Inc.

2955 George Washington Way

Richland, WA 99352

T. P. Papazog7ou

Babcock and Wilcox Company

P. 0. Box 1260

Lynchburg, VA 24505

G. W. Parry

Combustion Engineering

1000 Prospect Hill Road

Windsor, CT 06095

M. L. Picklesimer

Division of Reactor Safety Research

Fuel Behavior Research Branch

U.S. Nuclear Regulatory Conmission

Washington, DC 20555
D. F. Ross, Jr.

Director

Division of Systems Integration

Office of Nuclear Reactor Regulation

U.S. Huclear Regula tory Commission

Washington, DC 20555

L. S. Rubenstein

Assistant Director

Division of Systems Integration

Office of Nuclear Reactor

Regulation

U.S. Nuclear Regulatory Commission

Washington, DC 20555

A. E. Scherer

Combustion Engineering

1000 Prospect Hill Road

Windsor, CT 06095

G. G. Sherwood

General Electric Company

Nuclear Energy Division

175 Curtner Avenue

San Jose, CA 95125

G. A. Sofer

Exxon Nuclear Company, Inc. 2955 George Washington Way

Richland, WA 99352

Victor Stello, Jr.

Director, Office of Inspection and Enforcement

U. S. Nuclear Regulatory Commission

Washington, DC 20555

R. L. Tedesco

Asst. Director for Reactor Safety

Division of Systems Integration

Office of Nuclear Reactor Reculation

U.S. Nuclear Regulatory Commission Washington, DC 20555 


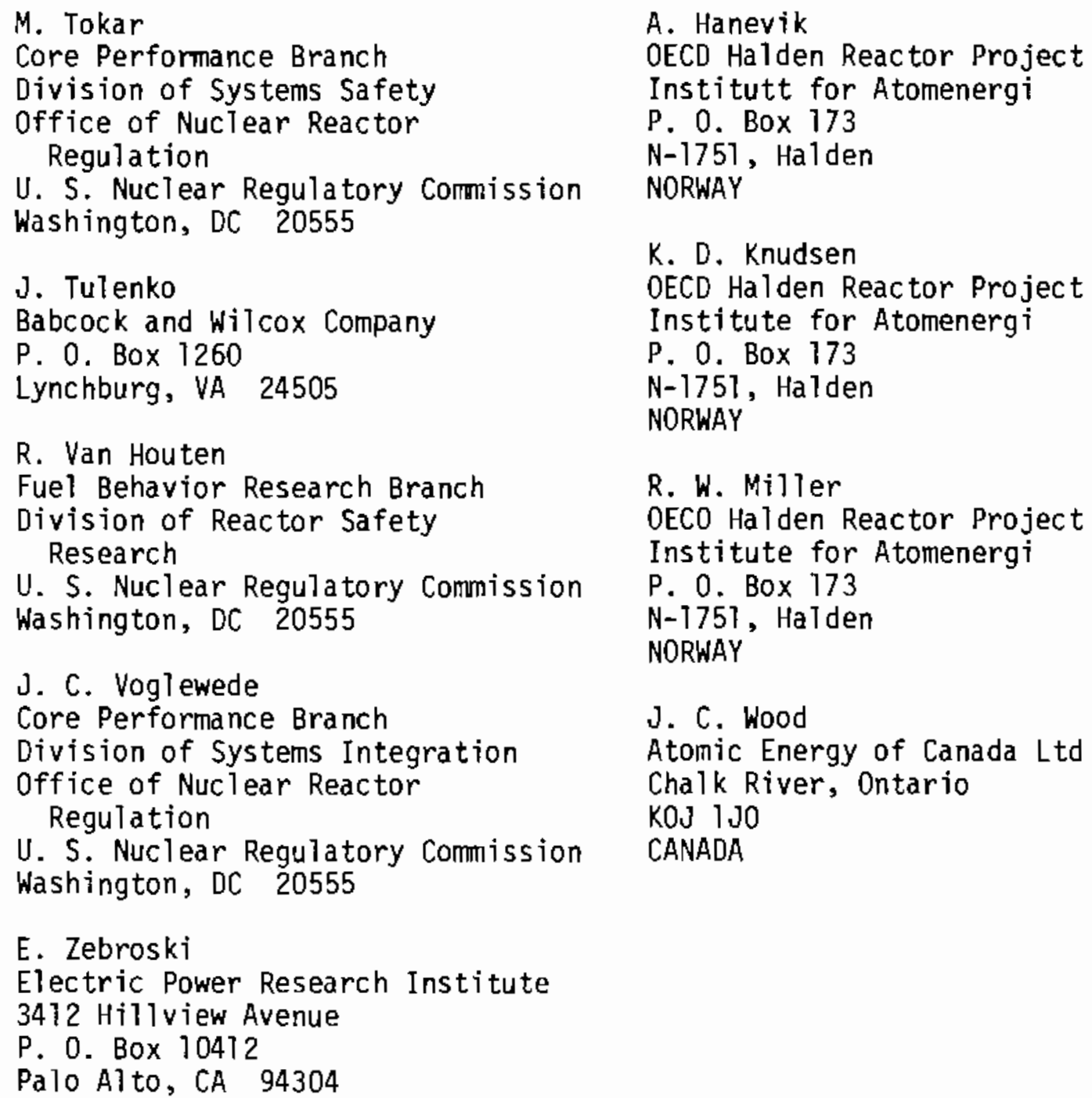

A. Hanevik

OECD Halden Reactor Project Institutt for Atomenergi

P. 0. Box 173

$\mathrm{N}-1751$, Halden

NORWAY

K. D. Knudsen

OECD Halden Reactor Project

Institute for Atomenergi

P. 0. Box 173

N-1751, Halden

NORWAY

R. W. Miller

OECO Halden Reactor Project Institute for Atomenergi

P. 0. Box 173

N-T751, HaTden

NORWAY

J. C. Wood

Atomic Energy of Canada Ltd Chalk River, Ontario

KOJ $1 \mathrm{JO}$

CANADA 


\section{ONSITE}

Pacific Northwest Laboratory

45 W. J. Bailey

J. 0. Barner

E. R. Bradley

M. E. Cunningham

R. L. Goodman

R. J. Guenther

C. R. Hann

D. C. Langstaff

D. D. Lanning

C. L. Mohr

F. E. Panisko (5)

P. J. Pankaskie (20)

W. N. Rausch

R. E. Schreiber

R. E. Williford

Technical Information (5)

Publishing Coordination RO (2) 




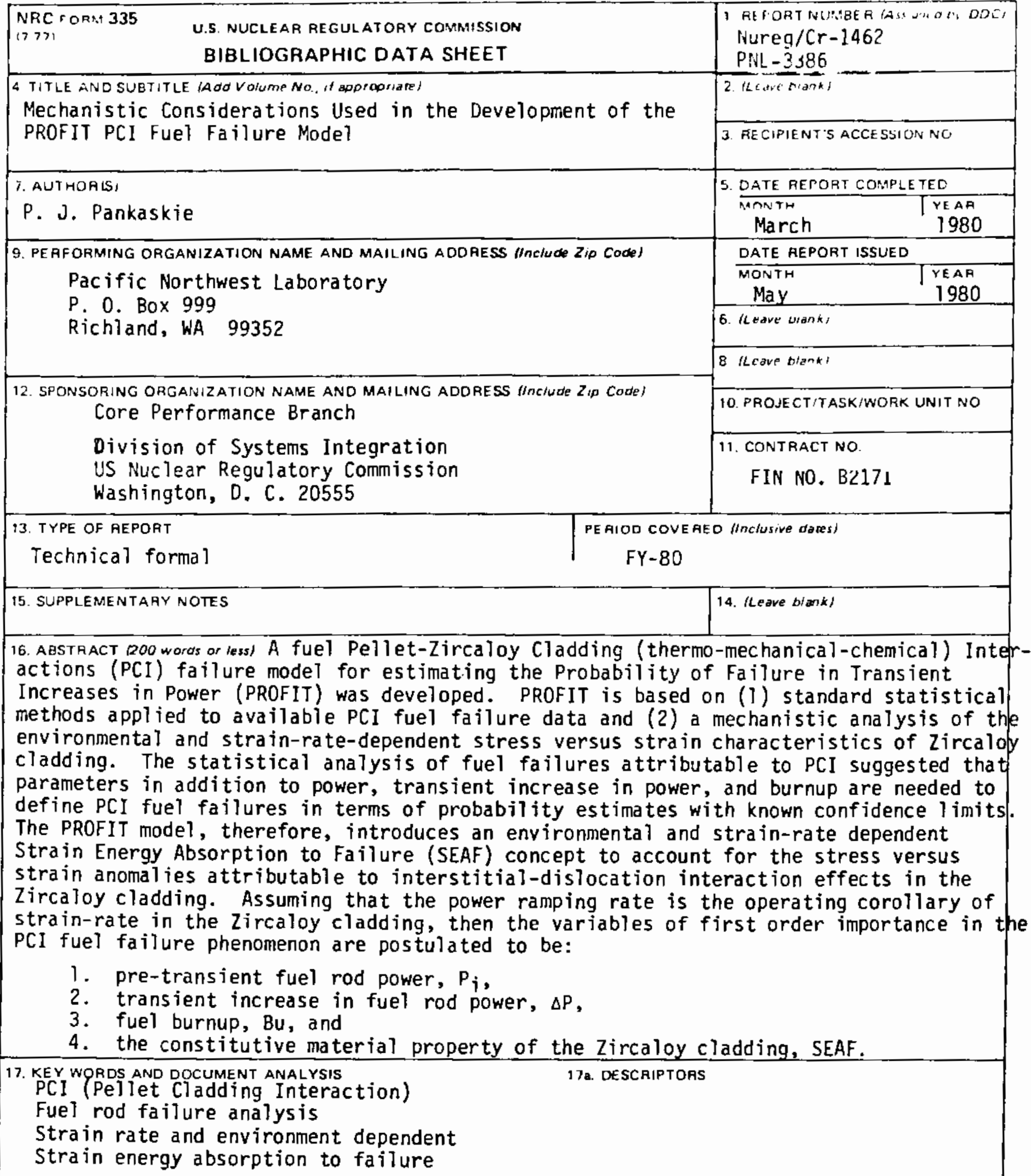

17b. IOENTIFIERS/OPEN-ENDED TERMS 
